\title{
Uncertainty in Unit Commitment in Power Systems: A Review of Models, Methods, and Applications
}

\author{
Ying-Yi Hong ${ }^{1, *(\mathbb{D})}$ and Gerard Francesco DG. Apolinario ${ }^{1,2} \mathbb{D}$ \\ 1 Department of Electrical Engineering, Chung Yuan Christian University, Taoyuan 32023, Taiwan; \\ gfrancesco.apolinario@tip.edu.ph \\ 2 Electrical Engineering Department, Technological Institute of the Philippines, Manila 1001, Philippines \\ * Correspondence: yyhong@ee.cycu.edu.tw
}

Citation: Hong, Y.-Y.; Apolinario,

G.F.D. Uncertainty in Unit

Commitment in Power Systems: A Review of Models, Methods, and

Applications. Energies 2021, 14, 6658.

https://doi.org/10.3390/

en14206658

Academic Editor: Tek Tjing Lie

Received: 31 August 2021

Accepted: 11 October 2021

Published: 14 October 202

Publisher's Note: MDPI stays neutral with regard to jurisdictional claims in published maps and institutional affiliations.

Copyright: (c) 2021 by the authors. Licensee MDPI, Basel, Switzerland. This article is an open access article distributed under the terms and conditions of the Creative Commons Attribution (CC BY) license (https:// creativecommons.org/licenses/by/ $4.0 /)$.
Abstract: The unit commitment problem (UCP) is one of the key and fundamental concerns in the operation, monitoring, and control of power systems. Uncertainty management in a UCP has been of great interest to both operators and researchers. The uncertainties that are considered in a UCP can be classified as technical (outages, forecast errors, and plugin electric vehicle (PEV) penetration), economic (electricity prices), and "epidemics, pandemics, and disasters" (techno-socio-economic). Various methods have been developed to model the uncertainties of these parameters, such as stochastic programming, probabilistic methods, chance-constrained programming (CCP), robust optimization, risk-based optimization, the hierarchical scheduling strategy, and information gap decision theory. This paper reviews methods of uncertainty management, parameter modeling, simulation tools, and test systems.

Keywords: chance-constrained programming; hierarchical scheduling strategy; information gap decision theory; probabilistic methods; risk-based optimization; robust optimization; stochastic programming; unit commitment problem; uncertainty

\section{Introduction}

A UCP involves the optimization of the ON/OFF states of generation units by minimizing the total operational cost while considering different constraints, in a particular period, generally one day/week. This problem arises mainly from the changing nature of human activities, which result in frequent load changes in each interval (minute, hour, day). Changes in load patterns require a change in available generation power plants. Mathematically, this problem is to optimize a set of completely mixed and nonlinear integer equations under different constraints to minimize the operational cost by solving the optimal combination of units from all possible scenarios.

In the last century, the UCP has continued to be significant, on account of developments and other changes in the power industry. Environmental policies, restructuring, privatization of the grid, penetration of RE, and the advent of smart grids have resulted in many changes and randomness in the power grid.

Uncertainties associated with various input parameters in the grid have raised several operational issues for system operators and other stakeholders. According to Ebeed et al. [1], the uncertainties of the parameters can be classified into two general categories: uncertainties of technical parameters and those of economic parameters. The COVID - 19 pandemic has resulted in an unexpected global economic and social dilemma [2], leading to the identification of a third category of "epidemics, pandemics, and disasters", all of which have techno-socio-economic effects on the energy sector.

Uncertainty affects schedules and may raise new challenges for the power grid. Various techniques and methods have been studied and employed to control the consequences of uncertainties associated with parameters. 
Different studies and reviews were published considering uncertainty management. Uncertainty management can be implemented using different decision - making techniques [3] and various system optimization algorithms [4-7]. Abujarad et al. [5] discussed different optimization approaches for a UCP considering intermittent renewable energy resources. Dai et al. [6] provided a summary of different SP applications in a UCP. Lastly, Jurković et al. [7] highlighted the advantages and disadvantages of commonly used methods (stochastic, robust, and interval) in UCPs for uncertainty management. Unlike previous studies, this paper will focus on a review of previously implemented methods such as stochastic programming, probabilistic methods, CCP, RO, risk-based optimization, hierarchical scheduling strategy, and IGDT in uncertainty management considering technical, economical, and "epidemics, pandemics, and disasters" parameters.

The objectives of this paper are as follows:

1. Delve into research that has considered uncertainty in the unit commitment problem.

2. Discuss models, methods, test systems, and simulation tools that are used for uncertainty management.

3. General comparison of different methods in terms of hardware specification, solver, run - time, and results.

This paper is structured as follows: Section 2 formulates the general unit commitment problem. Section 3 shows the modeling of different uncertainties that are considered in relation to unit commitment. Section 4 briefly reviews methods or techniques that are used to address these uncertainties. Section 5 addresses the different constraints that are applied in each method as well as the implemented test systems and simulation tools. Section 6 presents general notes on reviewed methods or techniques in addressing uncertainties. Lastly, Section 7 concludes by presenting the most important findings.

\section{Unit Commitment Formulation}

A UCP is a high-dimensional, mixed-variable, and complex problem because of its combinatorial behavior. The UCP involves the minimization of cost or maximization of profit. The formulation in this section involves all commonly used cost functions and constraints from various studies. Section 5 will summarize them.

\subsection{Objective Function}

The general expression of the objective function in the UCP is minimizing the total cost of running all the units for a given time. The difference between TC and TR is defined as,

$$
\begin{gathered}
\text { Minimize } \sum_{\mathrm{i}}^{\mathrm{N}_{\mathrm{g}}} \sum_{\mathrm{t}}^{\mathrm{T}}\left(\mathrm{TC}_{\mathrm{i}}^{\mathrm{t}}-\mathrm{TR}_{\mathrm{i}}^{\mathrm{t}}\right) \\
\text { or } \\
\text { Maximize } \sum_{\mathrm{i}}^{\mathrm{N}_{\mathrm{g}}} \sum_{\mathrm{t}}^{\mathrm{T}}\left(\mathrm{TR}_{\mathrm{i}}^{\mathrm{t}}-\mathrm{TC}_{\mathrm{i}}^{\mathrm{t}}\right)
\end{gathered}
$$

where TC, or total operation cost, is specified mainly in terms of fuel cost, shutdown, start-up, emissions, and social welfare cost. TR represents the total revenue because of market involvement. The essential parameter that affects TR is the payment method, which is specified in terms of market operations and market-clearing mechanisms. All of these must be optimized by taking into account the constraints that govern the problem. In the classical UCP, TR is not considered because the market is regulated.

\subsection{Different Terms of Objective Function}

Section 2.2 presents the terms associated with TC and TR.

\subsubsection{Total Cost Terms}

The five cost terms are fuel, start-up, shutdown, emission, and social welfare cost functions. 
TC is calculated as,

$$
\mathrm{TC}_{\mathrm{i}}^{\mathrm{t}}=\sum_{\mathrm{i}=1}^{\mathrm{N}_{\mathrm{g}}} \sum_{\mathrm{t}=1}^{\mathrm{T}} \mathrm{F}_{\mathrm{i}}\left(\mathrm{P}_{\mathrm{gi}}^{\mathrm{t}}+\mathrm{R}_{\mathrm{gi}}^{\mathrm{t}}\right) \mathrm{X}_{\mathrm{i}}^{\mathrm{t}}+\mathrm{SUC}_{\mathrm{i}} \mathrm{X}_{\mathrm{i}}^{\mathrm{t}}+\mathrm{SDC}_{\mathrm{i}}\left(1-\mathrm{X}_{\mathrm{i}}^{\mathrm{t}}\right)
$$

The social welfare and emission functions are not directly included in the TC term and will be considered in a multi-objective optimization framework.

\section{Fuel Cost Function}

The fuel cost function of a thermal generator is given in quadratic form. The conventional form of this function is as follows.

$$
F_{i}\left(P_{g i}^{t}+R_{g i}^{t}\right)=a_{i}+b_{i}\left(P_{g i}^{t}+R_{g i}^{t}\right)+c_{i}\left(P_{g i}^{t}+R_{g i}^{t}\right)^{2}
$$

Emission Function

Emission function is presented in a non-linear form as follows.

$$
E_{\mathrm{i}}\left(\mathrm{P}_{\mathrm{gi}}^{\mathrm{t}}+\mathrm{R}_{\mathrm{gi}}^{\mathrm{t}}\right)=\alpha_{\mathrm{i}}+\beta_{\mathrm{i}}\left(\mathrm{P}_{\mathrm{gi}}^{\mathrm{t}}+\mathrm{R}_{\mathrm{gi}}^{\mathrm{t}}\right)+\gamma_{\mathrm{i}}\left(\mathrm{P}_{\mathrm{gi}}^{\mathrm{t}}+\mathrm{R}_{\mathrm{gi}}^{\mathrm{t}}\right)^{2}+\xi_{i} e^{\lambda_{i}\left(\mathrm{P}_{\mathrm{gi}}^{\mathrm{t}}+\mathrm{R}_{\mathrm{gi}}^{\mathrm{t}}\right)}
$$

Social Welfare Function

Social welfare function involves the so-called penalty cost function. Social welfare is maximized when this penalty cost function is minimized. Table 1 shows the different models of this function and the studies that consider them.

Table 1. Different Models of Penalty Cost (Social Welfare) Function.

\begin{tabular}{cc}
\hline Study & Model \\
\hline$[8-41]$ & Load Shedding \\
\hline$[10,24,27,30-33,39,40,42-47]$ & Wind Spillage \\
\hline$[12,48]$ & Fuel Consumption \\
\hline$[12,32,48]$ & Emission Allowance \\
\hline$[12,18,31,41,49-52]$ & Replacement Reserve Penalty \\
\hline$[12,18,31,41,49-51,53]$ & Spinning Reserve Penalty \\
\hline$[15-18]$ & Transmission Capacity/Ramp - Rate Limit Violations \\
\hline$[25,29]$ & RE Curtailment \\
\hline$[44]$ & BESS Charge and Discharge Index \\
\hline
\end{tabular}

\section{Start-Up Cost}

In a thermal power plant, the start-up cost varies on fuel and emission prices, along with depreciation costs. These costs vary on off-time and therefore on a generator's temperature at the time when it is started up again. Mostly, a basic approach is implemented to specify the start - up cost. This cost is a function of the operational status of the thermal generator and can be allocated into cold and hot start - up costs, as follows.

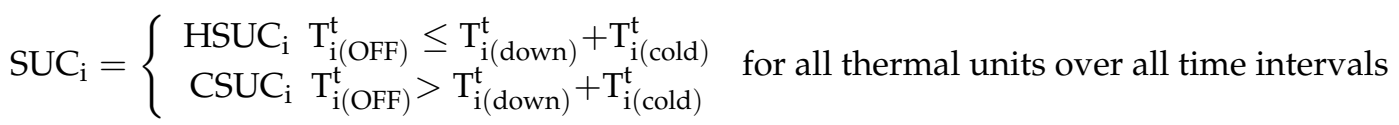

The start - up cost of a thermal generator is modeled as,

$$
\operatorname{SUC}_{\mathrm{i}}=\operatorname{CSSMC}_{\mathrm{i}}+\operatorname{CSUC}_{\mathrm{i}}\left(1-\mathrm{e}^{\left(\frac{\mathrm{SX}_{\mathrm{i}}^{\mathrm{t}}(\mathrm{OFF})}{C \mathrm{C}_{\mathrm{i}}}\right)}\right)
$$




\section{Shutdown Cost}

Most of the time, the shutdown cost is constant. This cost is developed as a constant term for each thermal generator, which is shut down in a specified hour.

\subsubsection{Total Revenue of Generation Companies}

The total revenue is taken from the sales of power. The three main approaches for payment are PPD, PRA, and PPRP. Abdi reviewed these methods [54].

\subsection{Problem Constraints}

This subsection presents the primary constraints in the UCP.

\subsubsection{System Constraints}

System constraints, known as global constraints, are important in the UCP. The main system constraints are as follows.

System Energy Balance or Real Power Constraints

$$
\sum_{\mathrm{i}=1}^{\mathrm{N}} \mathrm{P}_{\mathrm{gi}}^{\mathrm{t}} \mathrm{X}_{\mathrm{i}}^{\mathrm{t}} \leq \mathrm{P}_{\mathrm{d}}^{\mathrm{t}} \mathrm{t}=1, \ldots, \mathrm{T}
$$

Energy Constraints

$$
\mathrm{E}_{\mathrm{i}}^{\mathrm{min}} \leq \sum_{\mathrm{i}=1}^{\mathrm{N}} \mathrm{P}_{\mathrm{gi}}^{\mathrm{t}} \mathrm{X}_{\mathrm{i}}^{\mathrm{t}} \leq \mathrm{E}_{\mathrm{i}}^{\mathrm{MAX}}
$$

Reserve Constraints

$$
\sum_{i=1}^{N} R_{g i}^{t} X_{i}^{t} \geq S R^{t} t=1, \ldots, T
$$

Transmission Losses

The transmission losses are considered as follows.

$$
\mathrm{P}_{\text {loss }}^{\mathrm{t}}=\sum_{\mathrm{i}=1}^{\mathrm{N}_{\mathrm{g}}} \sum_{\mathrm{j}=1}^{\mathrm{N}_{\mathrm{g}}} \mathrm{P}_{\mathrm{gi}}^{\mathrm{t}} \mathrm{B}_{\mathrm{i}, \mathrm{j}} \mathrm{P}_{\mathrm{gj}}^{\mathrm{t}}+\sum_{\mathrm{i}=1}^{\mathrm{N}_{\mathrm{g}}} \mathrm{B}_{0} \mathrm{P}_{\text {gi }}^{\mathrm{t}}+\mathrm{B}_{00}
$$

\subsubsection{Unit Constraints (Local Constraints)}

Unit constraints are the local constraints that are considered on each generating unit. They are as follows.

Power Unit Limits

$$
\mathrm{P}_{\mathrm{gi}}^{\min } \leq \mathrm{P}_{\mathrm{gi}}^{\mathrm{t}} \leq \mathrm{P}_{\mathrm{gi}}^{\mathrm{MAX}}, \mathrm{i}=1, \ldots, \mathrm{N}
$$

Reserve Unit Limits

$$
\begin{gathered}
0 \leq \mathrm{R}_{\mathrm{gi}}^{\mathrm{t}} \leq \mathrm{P}_{\mathrm{gi}}^{\mathrm{MAX}}-\mathrm{P}_{\mathrm{gi}}^{\mathrm{min}}, \mathrm{i}=1, \ldots, \mathrm{N} \\
\mathrm{P}_{\mathrm{gi}}^{\mathrm{t}}+\mathrm{R}_{\mathrm{gi}}^{\mathrm{t}} \leq \mathrm{P}_{\mathrm{gi}}^{\mathrm{MAX}}, \mathrm{i}=1, \ldots, \mathrm{N}
\end{gathered}
$$


Unit Minimum Up/Down Times (MUT/MDT)

$$
\mathrm{U}_{\mathrm{i}}^{\mathrm{t}}=\left\{\begin{array}{c}
1 ; \mathrm{T}_{\mathrm{i}-\mathrm{ON})}^{\mathrm{t}-1} \leq \mathrm{T}_{\mathrm{i}}^{\mathrm{up}} \\
1 ; \mathrm{T}_{\mathrm{i}(\mathrm{OFF})}^{\mathrm{t}} \leq \mathrm{T}_{\mathrm{i}}^{\text {down }} \\
1 \text { or } 0 ; \text { otherwise }
\end{array}\right.
$$

Ramp Rate Limits (RRLs)

$$
\begin{aligned}
& \mathrm{P}_{\mathrm{gi}}^{\mathrm{t}}-\mathrm{P}_{\mathrm{gi}}^{\mathrm{t}-1} \leq \mathrm{UR}_{\mathrm{i}} \\
& \mathrm{P}_{\mathrm{gi}}^{\mathrm{t}-1}-\mathrm{P}_{\mathrm{gi}}^{\mathrm{t}} \leq \mathrm{DR}_{\mathrm{i}}
\end{aligned}
$$

Unit Status Limits

Several units may be needed to be online at a specified duration (must run) or may become offline due to scheduled maintenance or forced outages (must not run), due to reliability issues, economic factors, or operating limitations.

\subsubsection{Security Constraints}

In the SCUCP, security constraints are developed as follows.

AC Power Flow Constraints

$$
\begin{gathered}
\mathrm{P}_{\mathrm{Bgp}}^{\mathrm{t}}-\mathrm{P}_{\mathrm{Bdp}}^{\mathrm{t}}-\mathrm{V}_{p}^{\mathrm{t}} \sum_{\mathrm{q}=1}^{\mathrm{N}_{\mathrm{g}}} \mathrm{V}_{q}^{\mathrm{t}}\left(\mathrm{G}_{\mathrm{pq}} \cos \theta_{p q}+\mathrm{B}_{p q} \sin \theta_{\mathrm{pq}}\right)=0 \mathrm{p} \epsilon\left(\mathrm{N}_{\mathrm{B}}-1\right) \mathrm{t}=1, \ldots, \mathrm{T} \\
\mathrm{Q}_{\mathrm{Bgp}}^{\mathrm{t}}-\mathrm{Q}_{\mathrm{Bdp}}^{\mathrm{t}}-\mathrm{V}_{p}^{\mathrm{t}} \sum_{\mathrm{q}=1}^{\mathrm{N}_{\mathrm{g}}} \mathrm{V}_{q}^{\mathrm{t}}\left(\mathrm{G}_{\mathrm{pq}} \sin \theta_{\mathrm{pq}}-\mathrm{B}_{\mathrm{pq}} \cos \theta_{\mathrm{pq}}\right)=0 \mathrm{p} \epsilon \mathrm{N}_{\mathrm{PQ}} \mathrm{t}=1, \ldots, \mathrm{T}
\end{gathered}
$$

Transmission Line MVA Flow Limits

$$
\text { MVAflow }_{\mathrm{pq}}^{\mathrm{t}} \leq \text { MVAflow }_{\mathrm{pq}}^{\mathrm{MAX}}
$$

Bus Voltage Constraints

$$
\mathrm{V}_{\mathrm{q}}^{\min } \leq \mathrm{V}_{\mathrm{q}}^{\mathrm{t}} \leq \mathrm{V}_{\mathrm{q}}^{\mathrm{MAX}}
$$

\section{Modeling of Uncertainty}

The challenges that are raised by uncertain parameters in the power grid have encouraged operators to use different uncertainty modeling techniques to prepare for their consequences and to make the best decisions. Table 2 shows works concerning each category of uncertainty.

The uncertainties of parameters can be classified as technical, economic, and "epidemics, pandemics, and disasters". The following subsection will describe each model of uncertain parameters in the power system. 
Table 2. Studies Concerning Uncertainty Parameters in Unit Commitment Problem.

\begin{tabular}{|c|c|c|}
\hline Category & Description & Related Works \\
\hline \multirow{5}{*}{$\begin{array}{c}1 \\
\text { (Technical) }\end{array}$} & $\begin{array}{l}\text { outage or failure of any } \\
\text { element (lines, generators, or others) }\end{array}$ & {$[20,21,28,46,53,55-72]$} \\
\hline & load demand alteration/load growth & {$[9-12,17,18,21,23-25,27-34,41,43,47-50,53,55-58,60-64,66,70-85]$} \\
\hline & renewable output (wind, PV, etc.) & {$[9,10,12-17,22-35,38-45,47,49,51,53,55,57,58,60,65-76,78,79,81-111]$} \\
\hline & Fluctuation & {$[11,13,24,35,44,50,65,74,76,112,113]$} \\
\hline & uncertain penetration of PEVs & {$[55,70,72,75,86,87,104,114]$} \\
\hline $\begin{array}{c}2 \\
\text { (Economic) }\end{array}$ & variations in electricity market price & {$[11,16,18,19,24,43,61,81,83,84,103,109,115]$} \\
\hline 3 & epidemics, pandemics, and disasters & {$[36,100,116]$} \\
\hline
\end{tabular}

\subsection{Outage or Failure of Any Element (Lines, Generators, or Others)}

The uncertain parameter in the power system considering failure or outages is obtained using different reliability indices. These reliability indices can be classified as deterministic or probabilistic. Table 3 identifies each parameter, based on the work of Albrecht et al. [117].

Table 3. Various Reliability Indices in Power System.

\begin{tabular}{cc}
\hline Deterministic Indices & Probabilistic Indices \\
\hline & HLOLE \\
Percent reserve based on peak load & LOLE/LOLP \\
Percent reserve based on installed capacity & POPM \\
Reserve equal to several large units & $\mathrm{Q}$ \\
Maximum load not supplied & PLOL \\
Maximum energy not supplied & EENS \\
Minimum load supplying capability & XLNS/XLOL \\
Minimum simultaneous interchange capability & FLOL \\
Maximum line flow & DLOL \\
& BPII \\
& BPECI \\
\hline
\end{tabular}

\subsection{Load Demand Uncertainty Model}

The uncertainty of load demand can be developed using Gaussian or normal PDFs. The PDF of load demand can be stated as follows. [9,24,30,34,53,60,64,66,73,81]

$$
\mathrm{f}_{\mathrm{L}}\left(\mathrm{P}_{\mathrm{D}}\right)=\frac{1}{\sqrt{2 \pi \sigma_{\mathrm{D}}}} \mathrm{e}^{\left(-\frac{\left(\mathrm{P}_{\mathrm{D}}-\mu_{\mathrm{D}}\right) 2}{2 \sigma_{\mathrm{D}}^{2}}\right)}
$$

\subsection{Wind Energy Uncertainty Model}

Wind speed is an important parameter in determining wind energy output. The distribution of wind speeds can be modeled as a Weibull PDF or as Rayleigh PDF. Equations (22) and (23) describe the Weibull PDF and Rayleigh PDF of wind speed [23], respectively.

$$
\begin{gathered}
\mathrm{f}_{\omega}(\omega)=\left(\frac{\beta}{\alpha}\right)\left(\frac{\omega}{\alpha}\right)^{\beta-1} \mathrm{e}^{\left(-\left(\frac{\omega}{\alpha}\right)^{\beta}\right)} 0 \leq \mathrm{V}<\infty \\
\mathrm{f}_{\omega}(\omega)=\left(\frac{2 \omega}{\alpha^{2}}\right) \mathrm{e}^{\left(-\left(\frac{\omega^{2}}{\alpha^{2}}\right)\right)}
\end{gathered}
$$

A Weibull PDF with $\beta=2$ is called a Rayleigh PDF.

The output wind power can be expressed by means of various models. Table 4 presents commonly used models. 
Table 4. Models for Determining Wind Energy Output.

\begin{tabular}{|c|c|c|}
\hline & Model & Study \\
\hline $\mathrm{P}_{\mathrm{W}}(\omega)=\{$ & $\begin{array}{c}0 \text { for } \omega<\omega_{\mathrm{i}} \text { and } \omega>\omega_{\mathrm{o}} \\
\operatorname{P}_{\mathrm{r}}\left(\frac{\omega-\omega_{\mathrm{i}}}{\omega_{\mathrm{r}}-\omega_{\mathrm{i}}}\right) \text { for }\left(\omega_{\mathrm{i}} \leq \omega \leq \omega_{\mathrm{r}}\right) \\
\mathrm{P}_{\mathrm{r}} \text { for }\left(\omega_{\mathrm{r}}<\omega \leq \omega_{\mathrm{o}}\right)\end{array}$ & [42,118-123] \\
\hline & $\mathrm{P}_{\mathrm{W}}(\omega)=\frac{1}{2} \rho \mathrm{AV}^{3} \mathrm{C}_{\mathrm{p}}$ & {$[29,110,124]$} \\
\hline $\mathrm{P}_{\mathrm{W}}(\omega)=\{$ & $\begin{array}{c}0 \text { for } \omega<\omega_{\mathrm{i}} \text { and } \omega>\omega_{\mathrm{o}} \\
\operatorname{P}_{\mathrm{r}}\left(\frac{\omega^{3}-\omega_{\mathrm{i}}^{3}}{\omega_{\mathrm{r}}^{3}-\omega_{\mathrm{i}}^{3}}\right) \text { for }\left(\omega_{\mathrm{i}} \leq \omega \leq \omega_{\mathrm{r}}\right) \\
\operatorname{P}_{\mathrm{r}} \text { for }\left(\omega_{\mathrm{r}}<\omega \leq \omega_{\mathrm{o}}\right)\end{array}$ & {$[49,125]$} \\
\hline $\mathrm{P}_{\mathrm{W}}(\omega)=\{$ & $\begin{array}{c}0 \text { for } \omega<\omega_{\mathrm{i}} \text { and } \omega>\omega_{\mathrm{o}} \\
\operatorname{Pr}_{\mathrm{r}}\left(\frac{\omega^{2}-\omega_{\mathrm{i}}^{2}}{\omega_{\mathrm{r}}^{2}-\omega_{\mathrm{i}}^{2}}\right) \text { for }\left(\omega_{\mathrm{i}} \leq \omega \leq \omega_{\mathrm{r}}\right) \\
\operatorname{P}_{\mathrm{r}} \text { for }\left(\omega_{\mathrm{r}}<\omega \leq \omega_{\mathrm{o}}\right)\end{array}$ & [126] \\
\hline
\end{tabular}

\subsection{PV Energy Uncertainty Model}

The PV energy output is affected by the irradiance at the location. The probability distribution of irradiance is represented as a lognormal PDF as follows [127-129].

$$
\mathrm{f}_{\mathrm{S}}\left(\mathrm{G}_{\mathrm{S}}\right)=\frac{1}{\mathrm{SI} \sigma_{\mathrm{S}} \sqrt{2 \pi}} \mathrm{e}^{\left(-\frac{\left(\ln (\mathrm{SI})-\mu_{\mathrm{S}}\right)^{2}}{2\left(\sigma_{\mathrm{S}}\right)^{2}}\right)}
$$

The probability distribution of solar irradiance can also be expressed using the Beta distribution function as follows.

$$
\mathrm{f}_{\mathrm{T}}(\mathrm{T})= \begin{cases}\frac{\Gamma(\alpha+\beta)}{\Gamma(\alpha)+\Gamma(\beta)} \times \mathrm{SI}^{\alpha-1} \times(1--\mathrm{SI})^{\beta-1} & \text { if } 0 \leq-\mathrm{SI} \leq 1,0 \leq \alpha, \beta \\ 0 & \text { otherwise }\end{cases}
$$

where $\beta$ and $\alpha$ are parameters in the beta probability function. The parameter of the Beta PDF can be assessed using the standard deviation and mean of the random variable [128,129]:

$$
\begin{gathered}
\beta=\left(1-\mu_{\mathrm{S}}\right) \times\left(\frac{\mu_{\mathrm{S}} \times\left(1+\mu_{\mathrm{S}}\right)}{\sigma_{\mathrm{S}}^{2}}\right)-1 \\
\sigma_{\mathrm{S}}=\left(1-\mu_{\mathrm{S}}\right) \times\left(\frac{\mu_{\mathrm{S}} \times \beta}{1-\mu_{\mathrm{S}}}\right)-1
\end{gathered}
$$

The output PV power can be expressed using different models. Table 5 presents commonly used models.

Table 5. Models for Determining PV Power Output.

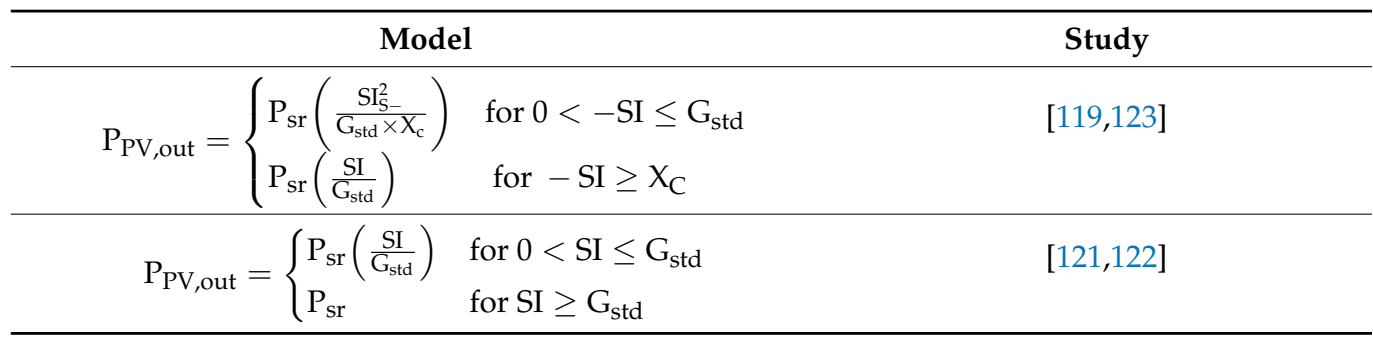


Table 5. Cont.

\begin{tabular}{|c|c|}
\hline Model & Study \\
\hline $\mathrm{P}_{\mathrm{a}}(\mathrm{SI})=\int \mathrm{P}(\mathrm{SI}) \cdot \mathrm{f}(\mathrm{SI}) \cdot \mathrm{dSI}$ & {$[78,129]$} \\
\hline $\mathrm{P}_{\mathrm{PV}, \text { out }}=\zeta_{\mathrm{PV}} \times \mathrm{A}_{\mathrm{PV}} \times \mathrm{SI}$ & {$[110,130]$} \\
\hline 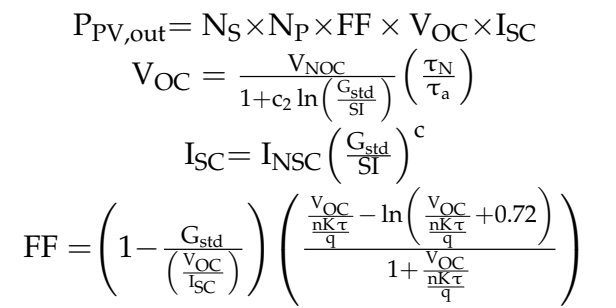 & [118] \\
\hline $\begin{array}{c}\mathrm{P}_{\mathrm{PV}, \text { out }}=\mathrm{N}_{\mathrm{S}} \times \mathrm{N}_{\mathrm{P}} \times \mathrm{FF} \times \mathrm{V}_{\mathrm{OC}} \times \mathrm{I}_{\mathrm{SC}} \\
\mathrm{I}=\mathrm{G}_{\mathrm{a}}\left[\mathrm{I}_{\mathrm{SC}}+\mathrm{K}_{\mathrm{i}}\left(\tau_{\mathrm{C}}-25\right)\right] \\
\mathrm{V}=\mathrm{V}_{\mathrm{OC}}-\mathrm{K}_{\mathrm{V}} \times \tau_{\mathrm{c}} \\
\mathrm{FF}=\frac{\mathrm{V}_{\mathrm{mpp}} \times \mathrm{I}_{\mathrm{mpp}}}{\mathrm{V}_{\mathrm{oc}} \times \mathrm{I}_{\mathrm{oc}}}\end{array}$ & {$[127,128]$} \\
\hline $\begin{array}{c}P_{P V}(t)=\frac{S I(t)}{1000} \times P_{S r} \times \eta_{P V} \times\left[1-\beta_{T}\left(\tau_{C}-25\right)\right] \\
\tau_{C}=25+(N O C T-20) \times \frac{S I(t)}{800}\end{array}$ & {$[74,125]$} \\
\hline
\end{tabular}

\subsection{PEVs Uncertainty Model}

The random nature of PEVS were considered and modeled using normal or Gaussian PDFs [127,131]. Table 6 presents various random variables that are related with PEVs. The PEV's daily arrival time is a common random variable that can be considered in the modeling uncertainties associated with PEV.

Table 6. Random Variables Concerning PEVs.

\begin{tabular}{cc}
\hline Random Variable & Study \\
\hline daily arrival time (initial parking time) & {$[55,70,75,86,114,127]$} \\
\hline initial state of charge (SOC) of the EV battery & {$[72,86,87,127,131]$} \\
\hline vehicle travel (distance) & {$[55,70,75,86,87]$} \\
\hline charge and discharge power of the EV & {$[55,72,87,125,131]$} \\
\hline
\end{tabular}

\subsection{Load Growth Uncertainty Model}

Load growth is essential information in the research of a power system; it is also considered to be a random parameter. $\mathrm{P}_{\mathrm{L}}(0)$ denotes the initial load in the base year while $\Delta \mathrm{P}_{\mathrm{L}}(\mathrm{y})$ is the incremental load growth in year $y$. Therefore, the load in year $y$ is $\mathrm{P}_{\mathrm{L}}(\mathrm{y})=\mathrm{P}_{\mathrm{L}}(0)+\Delta \mathrm{P}_{\mathrm{L}}(\mathrm{y})$. Its PDF can be expressed as follows [122]:

$$
\mathrm{f}_{\Delta \mathrm{P}_{\mathrm{L}}}\left(\Delta \mathrm{P}_{\mathrm{L}}\right)=\frac{1}{\sigma_{\Delta \mathrm{P}_{\mathrm{L}}} \sqrt{2 \pi}} \mathrm{e}^{\left(-\frac{\left(\Delta \mathrm{P}_{\mathrm{L}}-\mu_{\Delta \mathrm{P}_{\mathrm{L}}}\right) 2}{2\left(\sigma_{\Delta \mathrm{P}_{\mathrm{L}}}\right)^{2}}\right)}
$$

\subsection{Electricity Price Uncertainty Model}

Electricity price bought from the grid can also cause uncertainties in power system operation. The PDF of the electric price can be expressed as follows. [120,132]

$$
f_{E P}(E P)=\frac{1}{\sigma_{E P} \sqrt{2 \pi}} e^{\left(-\frac{\left(E P-\mu_{E P}\right)^{2}}{2\left(\sigma_{E P}\right)^{2}}\right)}
$$




\subsection{Epidemics, Pandemics, and Disasters}

Natural disasters such as typhoons, droughts, tsunamis, and earthquakes may generate uncertainty in the power grid. No base model exists for this category as each type of disaster can have certain consequences in the system (it can cause outages of power system components, a deficiency of supply, or excess supply). Huang et al. modeled the spillage of water from hydropower plants as an uncertain parameter [100]. Arab et al. proposed a post-disaster model that considered whether a component was "damaged" or "functional" [116]. Components that are classified as "damaged" undergo repairs for a specified time, and the VOLL is included in the UCP. Zhao et al. considered the worst load forecasting and line failure scenario in the UCP after a hurricane has occurred [36]. Pandemics and epidemics are presently highly significant,--specifically due to the COVID-19 pandemic [2]. This category will motivate new studies and modeling techniques since it influences the energy sector not only techno-economically but socially as well.

\section{Different Methods Used for Uncertainty in Unit Commitment}

The previous section considered the models of different uncertain parameters in the power grid. Different methods are required to solve the UCP with these uncertain parameters. Ebeed et al. [1] and Majidi et al. [133] classified these methods as possibilistic, probabilistic, hybrid possibilistic - probabilistic, IGDT, robust optimization, and interval analysis. This section discusses the methods considered in the literature review.

\subsection{Stochastic Programming}

$\mathrm{SP}$ is an approach that is risk-neutral and optimizes the expected outcome over a known probability distribution. Li et al. provided a brief history and review of stochastic programming methods [134]. They also discussed instances of SP, such as two - stage SP, multistage SP, multistage SP that goes through endogenous uncertainty, and scenario tree generation that is data-driven. Table 7 presents studies in which stochastic programming was used and the uncertain parameters modeled.

Table 7. Studies that Use Stochastic Programming.

\begin{tabular}{|c|c|c|}
\hline Uncertainty Model & Ref. & Remarks \\
\hline Demand & [11] & $\begin{array}{l}\text { MCS is performed to generate possible outcomes. } \\
\quad \text { SAA replaces the expected value function. } \\
\text { The chance constraint is substituted by MILP reformulation. } \\
\text { The price - elastic demand curve can be acquired by historical and simulation } \\
\text { data analysis. }\end{array}$ \\
\hline Demand & [17] & $\begin{array}{l}\text { A low expected total cost results from the novel unified stochastic and RUC model } \\
\text { while ensuring system robustness. }\end{array}$ \\
\hline Wind Power & [12] & $\begin{array}{l}\text { The WILMAR model is used. This model consists of two parts: - the scheduling model } \\
\text { and STT. } \\
\text { The main use of STT is to create scenarios used as inputs to the scheduling model. } \\
\text { The STT is used to generate scenarios that are used as inputs to the scheduling model. } \\
\text { The required wind and load scenarios are generated through the MCS of the wind and } \\
\text { load forecast error coming from and based on an auto-regressive moving average model } \\
\text { that illustrates the wind speed forecast error. } \\
\text { The varied probable scenarios generated are then reduced in number using a scenario } \\
\text { reduction approach. } \\
>\quad \text { A stochastic, mixed - integer optimization model is applied for the scheduling model. }\end{array}$ \\
\hline
\end{tabular}


Table 7. Cont.

\begin{tabular}{clll}
\hline Uncertainty Model & Ref. & Remarks \\
\hline & $>\quad \begin{array}{l}\text { Wind generation uncertainty is presented using different scenarios that capture all } \\
\text { feasible realizations of the stochastic process. } \\
\text { Wind Power }\end{array}$ & {$[33] \quad \begin{array}{l}\text { An appropriate set of scenarios were generated using a time series model. } \\
\text { SP by market }- \text { clearing model was used to calculate the required reserve levels and } \\
\text { their associated costs on a daily time horizon. }\end{array}$}
\end{tabular}

Wind Power

- Proposes analytical EENS and LOLP indices to which wind power uncertainties

$>$ WECS is included in the ED problem model.

Wind Power

[42] $>$ Together with the classic ED factors, other factors that account for both the overestimation and the underestimation of available wind power are included.

Wind Power

\section{[43]}

This model optimizes the dispatch and commitment of power generating units in the electricity system by minimizing operating costs.

$>$ The scenario tree approach is used to model wind power uncertainty.

$>\quad$ The potential value of ESU in power systems with renewable penetration are determined using a two - step framework.

$>\quad$ The first step uses a stochastic unit commitment with energy storage and wind power generation forecast uncertainty.

Wind Power [51] $>$ In the second step, the stochastic unit commitment solution is applied to obtain a flexible schedule for energy storage in economic dispatch with a limited look-ahead horizon.

$>$ GP regression is applied to generate the wind scenarios which account for the errors in the NWP. wind forecasts, is proposed.

$>$ Stochastic unit commitment including input and rolling planning scenarios, based on

Wind Power

[58] $>$ STT is established that allows forecast error statistics to be modified and simplifies the study of the impacts of statistics on system operation and UC.

$>$ The proposed scheme differs from already known unit commitments in such a way of Wind Power [73] explicitly modeling the day - ahead predicted residual demand PDF, including the effect of wind power curtailment.

The forecasted sporadic wind power generation is included in the UCP and solved in the master problem.

$>$ Benders' cuts are generated and combined with the master problem to revise the Wind Power [89] commitment solution if the dispatch fails.

$>$ Possible scenarios are simulated by MCS to represent wind power volatility.

$>$ The computational requirement for simulating many scenarios are reduced by the scenario reduction technique.

> Describes a computational framework that combines an advanced NWP model in economic dispatch/stochastic unit commitment formulations.

Wind Power

[91] $>$ Enhances the NWP model with an ensemble - based uncertainty quantification approach that is realized in a distributed - memory parallel computing architecture. 
Table 7. Cont.

\begin{tabular}{|c|c|c|}
\hline Uncertainty Model & Ref. & Remarks \\
\hline Wind Power & [92] & $\begin{array}{l}\text { Comparison of interval optimization and scenario - based approaches to stochastic } \\
\text { SCUC are presented. } \\
>\quad \text { Monte Carlo simulation is used for scenario - based approach. } \\
>\quad \text { Lower and upper bounds are utilized in interval optimization. } \\
>\quad \text { The stochastic SCUC problem is formulated as an MILP problem. }\end{array}$ \\
\hline Wind Power & [95] & $\begin{array}{l}\text { Development of an Artificial Neural Network - based wind forecast model that } \\
\text { considers wind generation uncertainty by using the probabilistic concept of a } \\
\text { confidence interval. }\end{array}$ \\
\hline Wind Power & [96] & $\begin{array}{l}\text { The stochastic bottom - up electricity market model optimizes unit commitment taking } \\
\text { into account five kinds of market and considering the prediction error and stochastic } \\
\text { behavior of wind power generation. } \\
\text { It can be used to evaluate varying electricity prices and system costs because of wind } \\
\text { power integration and to study integration measures. }\end{array}$ \\
\hline
\end{tabular}

Wind power is approximated using a normal PDF.

$>\quad$ Many scenarios are generated by MCS in describing the stochastic nature of wind power output.

Wind Power [97] $>\quad$ The generated scenarios are separated into three types (typical, normal, extreme) using CFSDP.

$>$ Extreme scenarios are discovered to establish the on/off states of generators, and the typical scenarios are utilized to solve the day - ahead SCED problem.

\begin{tabular}{|c|c|c|c|}
\hline Wind Power & [107] & $>$ & $\begin{array}{l}\text { Novel formulation of FDCUCP. } \\
\text { The impact of wind uncertainty on FDCUCP is considered using interval - based } \\
\text { optimization. } \\
\text { The original nonlinear model is reformulated to an MILP problem using the } \\
\text { reformulation - linearization technique. }\end{array}$ \\
\hline $\begin{array}{l}\text { Wind Power and } \\
\text { Demand }\end{array}$ & [30] & $>$ & $\begin{array}{l}\text { The optimal schedule of generation units and the required flexible ramp and spinning } \\
\text { reserves on a daily horizon are implemented on a proposed stochastic NCUC model } \\
\text { that includes uncertainties of demand and wind power. } \\
\text { Reduction of scenarios in modeling demand and wind power uncertainties is } \\
\text { implemented using PEM. } \\
\text { Worst - case scenarios that are based on regional wind and demand variations are } \\
\text { defined and incorporated into the proposed model together with the PEM scenarios. }\end{array}$ \\
\hline $\begin{array}{l}\text { Wind Power and } \\
\text { Demand }\end{array}$ & [57] & $\begin{array}{l}> \\
>\end{array}$ & $\begin{array}{l}\text { This paper formulates a short - term forward electricity market clearing problem with } \\
\text { stochastic security that is capable of accounting for variable and non - dispatchable } \\
\text { wind power generation sources. } \\
\text { Demand is modeled using a normal distribution function. } \\
\text { Wind speed is modeled using a Rayleigh distribution function. }\end{array}$ \\
\hline Renewable Energy & [44] & $>$ & $\begin{array}{l}\text { Establishes a stochastic gas - power - network-constrained unit commitment model } \\
\text { that considers both combined - cycle units and gas networks. } \\
\text { ADP is proposed to prevent the curse of dimensionality. } \\
\text { Renewable energy output is modeled using a probabilistic distribution function. }\end{array}$ \\
\hline
\end{tabular}


Table 7. Cont.

\begin{tabular}{cccc}
\hline Uncertainty Model & Ref. & \multicolumn{1}{c}{ Remarks } \\
\hline $\begin{array}{c}\text { Renewable Energy and } \\
\text { Demand }\end{array}$ & $\quad$ [11] $\quad>\quad \begin{array}{l}\text { A stochastic programming model of the short - term peak shaving operation of a } \\
\text { photovoltaic - wind - hydro hybrid system is implemented. } \\
\text { The renewable energy production and load demand uncertainties are simulated using } \\
\text { scenario trees and synthetic ensemble forecasts. }\end{array}$
\end{tabular}

$>$ RTED is carried out every $5-15$ min using static snapshot forecast data.

Solar, Wind, and Demand

$>\quad$ The minute-to-minute variability of wind, PV, and demand on a given scheduling period is considered in the evaluation of "best-fit" PFs.

$>\quad$ The Weibull probability density function is obtained from the wind and solar profiles.

$>$ Load demand is modeled using a normal PDF.
$>$ Sug

Suggests a new stochastic framework based upon UT in modeling uncertainties related with PEVs' behaviors in considering the correlated WTs' power generation.
PEV, Demand and Wind Power

$>$ MCS is utilized in the proposed stochastic model.

$>$ PEV energy consumption patterns, load forecast errors, and the number of PEVs in a fleet are characterized by truncated normal PDFs.

- Wind speed variations are simulated by the Weibull PDFs, diurnal pattern, and auto correlation factor, and wind generation is found by incorporating it to a wind turbine power curve and wind speed at wind sites.

$>$ Forward backward and forward algorithms are created to reduce the number of scenarios while providing acceptable accuracy.

$>$ The scheduling of local electricity flows is presented using a central planner - decentral operator method.

> The central planner performs a two-stage optimization to derive the demand limit and a corresponding battery schedule. The decentral operator, on the other hand, applies the battery schedule and heuristically reacts to unforeseen deviations between the actual and forecasted generation and demand.

$>$ The reserve capacity and relaxation factor of the battery are derived from MCS that considers underlying uncertainties.

$>$ Utilizes three coordinated PEV - wind energy dispatching methods in the V2G context (variable - rate energy dispatching, interruptible, and valley searching) to encourage user demand response by optimizing the utilization efficiency of wind power generation and meet dynamic power demands.

PEV and Wind Power [87] > These approaches are addressed in a stochastic framework, considering the uncertainties.

- A comparative study involves numerical simulation experiments that cover adequate system scenarios using scenario generation and reduction techniques.

$>$ Scenario trees are used to generate the scenarios for electricity price uncertainty.

Power trading is included in the stochastic UC model.

Electricity Price [19] $>\quad$ Fuel constraints and prices are considered in the model that may change with electricity prices and demand.

$>$ Lagrangian relaxation and Bender's decomposition are applied in the MILP model.

Electricity Price Wind, Solar, and Demand
- A scenario-based technique is used in modelling the uncertainties of PV and WT output power, demand forecast errors, and grid bid changes for the optimal energy

[81] $>\quad$ MBA is used to optimize the energy management of the grid-connected microgrid with large uncertainties. 
Table 7. Cont.

\begin{tabular}{|c|c|c|}
\hline Uncertainty Model & Ref. & Remarks \\
\hline $\begin{array}{l}\text { Electricity Price } \\
\text { (Investment) } \\
\text { Load Growth }\end{array}$ & [83] & $\begin{array}{l}\text { The day-ahead reserve and energy markets, and real time operation are implemented } \\
\text { using a proposed two - stage SP. } \\
\text { Scenario tree is used to generate the investment and load growth model. }\end{array}$ \\
\hline $\begin{array}{l}\text { Electricity Price } \\
\text { Wind Power }\end{array}$ & [103] & $\begin{array}{l}\quad \text { Scenario generation (Roulette Wheel) is used to model uncertainty. } \\
\quad \text { The initial scenarios are reduced using SCENRED. } \\
\quad \text { A multi - objective offering strategy is proposed. }\end{array}$ \\
\hline $\begin{array}{l}\text { Electricity Price } \\
\text { Renewable Energy }\end{array}$ & [113] & $\begin{array}{l}\text { An innovative formulation for UBFUCC }{ }^{\text {DRRs is suggested. }} \\
\text { The price - elasticity of electrical consumption is modeled, as an uncertain, unavailable, } \\
\text { and hard - to - estimate parameter using Z numbers in a possibilistic - probabilistic } \\
\text { method. } \\
\text { Supply-side resource uncertainty is considered using MCS. }\end{array}$ \\
\hline $\begin{array}{l}\text { Electricity Price } \\
\text { Load GrowthPEV }\end{array}$ & [120] & MCS is used to model uncertainty. \\
\hline $\begin{array}{c}\text { Outages of Generation } \\
\text { Units }\end{array}$ & [20] & $\begin{array}{l}\quad \text { Random disturbances are modeled using scenario trees. } \\
\quad \text { The failure probability law used is binomial. } \\
\text { The use of an augmented Lagrangian technique provides the decomposition algorithm } \\
\text { with satisfactory convergence properties. }\end{array}$ \\
\hline
\end{tabular}

\begin{tabular}{|c|c|c|c|}
\hline $\begin{array}{l}\text { Outages of Generation } \\
\text { Units } \\
\text { Demand } \\
\text { Electricity Price }\end{array}$ & [21] & $>$ & Scenario generation is used to model the uncertainty. \\
\hline $\begin{array}{l}\text { Outages of Generation } \\
\text { Units and } \\
\text { Transmission Lines } \\
\text { Demand }\end{array}$ & [48] & $>$ & $\begin{array}{l}\text { Uncertainty modeled using scenario trees via MCS. } \\
\text { The scenario aggregation method and scenario reduction are used to reduce } \\
\text { computation time. }\end{array}$ \\
\hline $\begin{array}{l}\text { Outages of Generation } \\
\text { Units } \\
\text { Demand }\end{array}$ & [56] & $>$ & $\begin{array}{l}\text { Compares the reserve and stochastic approach and evaluates the benefits of a combined } \\
\text { method for the efficient management of uncertainty in the unit commitment problem. } \\
\text { Two-state Markov process is implemented in modeling the state of generation resources. } \\
\text { Uncertainty in the demand is handled by the addition of the stochastic forecast error. }\end{array}$ \\
\hline $\begin{array}{l}\text { Outages of Generation } \\
\text { Units Demand and } \\
\text { Wind Power }\end{array}$ & {$[60]$} & $\begin{array}{l}> \\
>\end{array}$ & $\begin{array}{l}\text { Load is modeled using a normal distribution function. } \\
\text { The } 2 \text { - state capacity model is used to represent generator availability. } \\
\text { ARMA is used to model wind speed variations. }\end{array}$ \\
\hline $\begin{array}{l}\text { Outages of Generation } \\
\text { Units } \\
\text { Wind, PV, and } \\
\text { Demand }\end{array}$ & [67] & $>$ & $\begin{array}{l}\text { The uncertainties due to generator outages, PV, wind, and demand forecast errors are } \\
\text { incorporated into the proposed optimization problem using EUE and LOLP } \\
\text { reliability indices. }\end{array}$ \\
\hline
\end{tabular}

\subsection{Probabilistic Methods}

A PDF is identified for each random input parameter. Numerical and analytical methods are the commonly known category of probabilistic approaches or uncertainty modeling methods. 


\subsubsection{Numerical Methods}

Numerical methods are mathematical tools used to find the uncertain input parameter. The main drawback of this method, also known as the conventional or purely mathematical method, is its high dimensionality and computing time. The following subsection will discuss MCS and MCMCS.

\section{Monte Carlo Simulation}

The MCS is applied to develop the probabilities of several outcomes of a process that cannot easily be predicted owing to the involvement of random variables. This is used to understand the impact of uncertainty and risk in forecasting and prediction models. Table 8 lists studies in which the MCS method was used and the uncertain parameters that were modeled in them. Most studies that use this method focus on renewable energy and demand as sources of uncertainty for the power grid.

Table 8. Studies In Which MCS Is Used.

\begin{tabular}{cc}
\hline Ref. & Uncertainty Model \\
\hline$[11]$ & Demand \\
\hline$[12]$ & Wind Power \\
\hline$[48]$ & Demand \\
\hline$[60]$ & Demand and Wind Power \\
\hline$[75]$ & Demand, PEV and PV \\
\hline$[89]$ & Wind Power \\
\hline$[92]$ & Wind Power \\
\hline$[97]$ & Wind Power \\
\hline$[113]$ & RE \\
\hline$[120]$ & Load Growth, Electricity Price and PHEV
\end{tabular}

\section{Markov Chain MCS}

MCMCS is a dynamic variation of the MCS method that is utilized to manage the uncertainty of parameters of a system. In this method, MCMCS is used to generate the samples based on the probability distribution, in which the probability of creating a unique state in the chain is based only on the present state.

In the MCMCS implementation, the probability of change is defined using the Metropolis method, which states that transition probability from state $m$ to $\bar{m}$, is $q(m, \bar{m})$ while the probability of the accepted state is $\alpha(\mathrm{m}, \overline{\mathrm{m}})$ [1].

Table 9 presents studies in which the MCMS method has been used and the uncertain parameters that are modeled in them.

Table 9. Studies In Which MCMS Is Used.

\begin{tabular}{cc}
\hline Ref. & Uncertainty Model \\
\hline$[46]$ & Outages of $\begin{array}{c}\text { Generation Units and Transmission } \\
\text { Lines }\end{array}$ \\
\hline$[56]$ & Outages of Generation Units \\
\hline$[60]$ & Outages of Generation Units \\
\hline
\end{tabular}

\subsubsection{Analytic Methods}

Different analytical methods (scenario - based and PDF approximation) are established for calculation with PDFs of uncertain input parameters. 


\section{Scenario-Based Method}

The scenario - based method is a simple and efficient method for developing probabilistic uncertainties in which the continuous space of an uncertain function is converted into discrete scenarios with subsequent probabilities, and the PDF curve is divided into subregions [1]. Each region denotes a scenario that has a particular probability. Suppose that the divided regions have $\mathrm{k}=1,2,3 \ldots, \mathrm{N}$ and their subsequent probabilities are $\mathrm{p}_{1}, \mathrm{p}_{2}$, $\mathrm{p}_{3}, \ldots, \mathrm{p}_{\mathrm{N}}$. The expected output value is given by,

$$
\mathrm{E}(\mathrm{y})=\sum_{\mathrm{k}=1}^{\mathrm{N}} \mathrm{p}_{\mathrm{k}} \times \mathrm{f}(\mathrm{x})
$$

The scenario-based method approximates and provides the expected values of the output functions.

Table 10 lists studies in which a scenario - based method is used, and the associated uncertain parameters. Scenario Trees are most used in the scenario-based method. Other methods include the WILMAR model, the PEM, GP regression, and the Roulette Wheel.

Table 10. Studies In Which Scenario-based Is Used.

\begin{tabular}{|c|c|c|}
\hline Ref. & Uncertainty Model & Approach/Technique \\
\hline [12] & Wind Power & WILMAR Model \\
\hline [19] & Electricity Prices & Scenario Trees \\
\hline [21] & $\begin{array}{c}\text { Outages of Generation } \\
\text { Units } \\
\text { Demand } \\
\text { Electricity Price }\end{array}$ & Scenario Generation (not stated) \\
\hline$[30]$ & $\begin{array}{l}\text { Wind Power and } \\
\text { Demand }\end{array}$ & PEM \\
\hline$[43]$ & Wind Power & Scenario Trees \\
\hline [48] & Demand & Scenario Trees \\
\hline [51] & Wind Power & GP Regression \\
\hline [58] & Wind Power & Scenario Trees \\
\hline [81] & $\begin{array}{l}\text { Wind, Solar, and } \\
\text { Demand } \\
\text { Electricity Price }\end{array}$ & The Scenario - Based Technique (not stated) \\
\hline [83] & $\begin{array}{l}\text { Load Growth } \\
\text { Electricity Price } \\
\text { (Investment) }\end{array}$ & Scenario Trees \\
\hline [103] & $\begin{array}{l}\text { Electricity Price } \\
\text { Wind Power }\end{array}$ & Scenario Generation (Roulette Wheel) \\
\hline [111] & $\begin{array}{c}\text { Renewable Energy and } \\
\text { Demand }\end{array}$ & Synthetic Ensemble Forecasts and Scenario Trees \\
\hline
\end{tabular}

\section{PDF Approximation}

Approximate methods provide a simple description of the uncertain parameters by random variables. The main advantage of these methods is the use of deterministic routines for solving the UCP. In addition, approximate methods are computationally more efficient than other probabilistic methods.

Table 11 presents studies in which the PDF approximation method was used, the uncertain parameters modeled, and the type of technique considered. This method has been mostly applied to uncertainties with demand and renewable energy. 
Table 11. Studies In Which PDF Approximation Is Used.

\begin{tabular}{ccc}
\hline Ref. & Uncertainty Model & Approach/Technique \\
\hline$[36]$ & Disaster (Hurricane) & Fast Kernel Density Estimation Algorithm \\
\hline$[74]$ & PV & Cornish - Fisher Expansion \\
\hline$[75]$ & PV and Demand \\
PEV & Kernel Distribution Estimation \\
\hline$[78]$ & PV and Demand & Gaussian Copula \\
\hline$[86]$ & PEV & Unscented Transformation \\
\hline$[104]$ & RE and Demand & $\begin{array}{c}\text { Maximum Entropy and Gram - Charlier } \\
\text { Probability Density Function Reconstructions }\end{array}$ \\
\hline$[112]$ & Wind Power & Nonparametric Density Estimators \\
\hline
\end{tabular}

\subsection{Chance Constrained Programming}

The core idea of conventional CCP is to permit constraint violation. The probability violation must be smaller than a predefined risk level (confidence interval). A general form of a chance constraint is as follows. [40]

$$
\operatorname{Pr}\left\{\mathrm{f}_{\mathrm{i}}(\mathrm{x}, \xi) \leq \mathrm{B}_{\mathrm{i}}\right\} \geq 1-\mathrm{A}_{\mathrm{i}}
$$

The symbol "Pr $\{\bullet\}$ " indicates the value of a probability.

CCP is regarded as solving a stochastic problem with some probabilistic constraints, such that certain constraints that are related to some uncertain parameters are fulfilled with a given probability.

Table 12 presents different studies in which CCP is used and the uncertain parameters modeled. A significant number of studies uses CCP to deal with uncertainties that are generated by wind power and demand.

Table 12. Studies In Which CCP Is Used.

\begin{tabular}{|c|c|c|}
\hline Uncertainty Model & Ref. & Remarks \\
\hline Wind Power & [9] & $\begin{array}{l}\text { This paper suggests an expected value and chance constrained stochastic optimization } \\
\text { approach to solve the UCP with uncertain wind power output. } \\
\text { The model utilizes the wind power generation by varying the utilization rate in the } \\
\text { proposed expected value constraint. } \\
>\quad \text { In the model, the utilization of wind power can be adjusted by changing the utilization } \\
\text { rate in the proposed expected value constraint. } \\
>\quad \text { The chance constraint is imposed to inhibit the probability of load imbalance. } \\
>\quad \text { The expected value and chance constraint, and the objective function are transformed } \\
\text { using SAA. }\end{array}$ \\
\hline Wind Power & [14] & $\begin{array}{l}\text { The problem is formulated as CCTS stochastic program. } \\
\text { The two-stage stochastic and chance - constrained stochastic program features were } \\
\text { included in the given model. } \\
\quad \text { The model is effectively solve using a combined SAA algorithm. }\end{array}$ \\
\hline Wind Power & {$[40]$} & $\begin{array}{l}\text { A novel CCGP model was proposed to optimize the risk adjustable UCP. } \\
\text { A tractable MILP resulted to the transformation of the proposed model using a } \\
\text { deterministic equivalent and piecewise linearization. }\end{array}$ \\
\hline
\end{tabular}


Table 12. Cont.

\begin{tabular}{|c|c|c|c|}
\hline Uncertainty Model & Ref. & & Remarks \\
\hline Wind Power & {$[45]$} & $>$ & $\begin{array}{l}\text { MILP - based chance - constrained optimization model is proposed to establish } \\
\text { efficiently the optimal wind power output ranges, which are quantified using } \\
\text { maximum and minimum wind generation levels in a certain time interval. } \\
\text { The developed wind power range is then used to create dynamic uncertainty intervals } \\
\text { for the robust SCUC model. }\end{array}$ \\
\hline Wind Power & [99] & $\begin{array}{l}> \\
>\end{array}$ & $\begin{array}{l}\text { Transforms the conventional UC model into a chance - constrained stochastic problem } \\
\text { to satisfy the optimal schedule objective. } \\
\text { The non - convex problem is solved by introducing the PSO algorithm and BB } \\
\text { technique; PSO is initialized using simplex algorithms. }\end{array}$ \\
\hline Wind Power & {$[108]$} & $>$ & A novel method for solving GRCC - RTD with wind power uncertainty is proposed. \\
\hline $\begin{array}{l}\text { Wind Power } \\
\text { Demand }\end{array}$ & {$[64]$} & $\begin{array}{l}> \\
>\end{array}$ & $\begin{array}{l}\text { A new approach for reserve scheduling and joint energy and reserve scheduling and } \\
\text { unit commitment under reliability constraints for the day - ahead market is provided. } \\
\text { The proposed method includes a novel } n-K \text { criterion under which load must be } \\
\text { satisfied with a specified probability under any instantaneous loss of } K \text { generating units. } \\
\text { A chance - constrained method is proposed with an } \alpha \text {-quantile measure to determine } \\
\text { the confidence level, where demand is met under } K \text { simultaneous contingencies. } \\
\text { The chance - constrained optimization problem CCP is recast as a MILP } \\
\text { optimization problem. }\end{array}$ \\
\hline
\end{tabular}

> The UCP is devised as a chance - constrained two - stage stochastic programming problem where the chance constraint is applied to limit the probability of load imbalance.

Wind Power

Demand

$>\quad$ derives its linear equivalent using the McCormick linearization method. easy-to-implement algorithm, to answer the resulting large - scale linear equivalent.

$>$ An optimal bidding strategy for independent power producers in a deregulated electricity market is proposed.

$>$ The problem is devised as a two - stage stochastic price - based UCP with chance constraints to ensure wind power operation.

$>$ The 1st stage decision includes unit commitment and the amount of electricity

Wind Power Electricity Price submitted to the day-ahead market.

$>\quad$ The 2nd stage outcome includes actual usage of wind power, generation dispatch, and energy imbalance among the day - ahead and real - time markets.

$>$ The chance constraint is utilized to guarantee a specific percentage of wind power operation to satisfy renewable energy utilization regulations.

$>$ SAA is applied to solve the problem.

$>$ The problem is devised as a chance - constrained two - stage stochastic programming model.

$>$ Three different policies are used to guarantee that the utilization of renewable energy is high in microgrid operations. interval while the 2nd and 3rd policies impose renewable energy utilization for certain hours and all operating hours, respectively.

$>$ A combined SAA algorithm is used in solving the proposed model. 
Table 12. Cont.

\begin{tabular}{|c|c|c|c|}
\hline Uncertainty Model & Ref. & & Remarks \\
\hline Renewable Energy & [110] & $>$ & $\begin{array}{l}\text { The method uses CCP to manage uncertainties in power that are generated by } \\
\text { renewable resources. } \\
\text { The design variables are the PV panel area, the number of batteries, and the rotor's } \\
\text { swept area. }\end{array}$ \\
\hline $\begin{array}{l}\text { Renewable Energy } \\
\text { Demand }\end{array}$ & [107] & $>$ & $\begin{array}{l}\text { The total storage power and energy constraints are presented as chance constraints, for } \\
\text { which conservative convex approximations are used for tractability. }\end{array}$ \\
\hline Fluctuation & [65] & $\begin{array}{l}> \\
> \\
> \\
>\end{array}$ & $\begin{array}{l}\text { Formulates a stochastic optimization program with chance constraints that determine } \\
\text { the probability of fulfilling the transmission capacity constraints on generation and the } \\
\text { lines limits. } \\
\text { The steady - state behavior of the secondary frequency controller is considered to } \\
\text { incorporate a reserve decision scheme. } \\
\text { Deployed reserves are taken as linear function of the total generation-load mismatch. } \\
\text { They are proposed for tractability. } \\
\text { A scenario - based approach and an approach that considers only the quantiles of the } \\
\text { stationary distribution of the wind power error are used in dealing the } \\
\text { chance constraint. }\end{array}$ \\
\hline
\end{tabular}

- A new electricity market - clearing structure based on LMPs is provided for assessing the uncertain generation and load.

Electricity Price $\quad[85] \quad>\quad$ U - LMP is developed from a distributionally robust chance - constrained optimal power flow model where only the 1st order and 2nd order moments of the uncertain sources' probability distribution are required.

PEV

Wind Power

Demand

\section{[106]}

- Uses a fuzzy CCP that considers wind power forecasting errors.

$>\quad$ The demand response and PEVs may change the demand curve to solve the mismatch problem.

$>$ A new method is introduced to manage uncertainties (Wind, PV, and PEVs) in the optimal sizing of DGs.

PEV

Wind Power

PV Power
$>$ A mathematical model of CCP is created with the minimization of the DGs' maintenance cost, network loss cost, capacity adequacy cost, operating cost, and the investment cost as the objective function, security limitations as constraints, and the sizing and siting of DGs as optimization variables.

> An MCS - embedded genetic - algorithm - based method is used in solving the developed CCP model.

\subsection{Robust Optimization}

$\mathrm{RO}$ methods are commonly used for uncertainty management in power systems. For instance, $\mathrm{RO}$ methods are used to solve the optimization problem with the worst scenario concerning the uncertain parameters.

Table 13 lists studies in which robust optimization is used and how this method is implemented for uncertain parameters. Different studies consider the uncertainty set to have fixed limits [15-18,22], while others model it as a flexible one [25,27,31]. MCS [17,94], PSO [82], and historical data $[15,22,29,114,115]$ are commonly used to generate the uncertainty set for the reviewed studies. 
Table 13. Studies In Which Robust Optimization Method Is Used.

\begin{tabular}{lll}
\hline Ref. & \multicolumn{1}{c}{ Method Implementation } \\
\hline$\quad \quad \begin{array}{l}\text { The random wind power output is model with an } \\
\text { uncertainty set. } \\
\text { The assumed uncertain wind power output is } \\
\text { within a given lower and upper limit. } \\
\text { The lower and upper limit can be found based on } \\
\text { an interval forecast or historical data. }\end{array} \quad \begin{array}{l}\text { Proposes an RO approach to accommodate wind output } \\
\text { uncertainty, and, to provide an RUC schedule for the thermal } \\
\text { generators in the day-ahead market that minimizes the total cost in } \\
\text { the worst wind power output scenario. } \\
\text { RO is used to model the randomness using an uncertainty set that } \\
\text { includes the worst-case scenario and keeps this scenario under the } \\
\text { minimal increment of costs. }\end{array}$
\end{tabular}

$>$ The uncertain wind power output is based on the uncertainty set with limit set at 0.95 and

[16] 0.05 quantiles.

$>\quad$ The demand response uncertainty set can be formulated using the price - elastic demand curve.
$>$ A multi-stage robust MIP problem.

$>$ An exact solution that uses Benders' decomposition is developed to obtain the optimal robust unit commitment schedule for the given problem. $>\quad$ In generating the uncertainty set for the robust optimization part, the assumed demand at each time in each bus is between an upper and a lower bound, which can be set as the 5th and 95th percentiles of random demand. $>\quad$ A novel unified robust and stochastic UC model can attain a low expected total cost while ensuring system robustness.

$>$ Introduces weights of the components for the robust and stochastic parts in the objective function, $\mathrm{SO}$ can adjust the weights according to preferences.

$>\quad$ The model is solved using Benders' decomposition algorithm.

$>\quad$ For the stochastic part, MCS is performed to generate scenarios for load uncertainty (stochastic part).
$>$ The uncertainty model in an RO formulation is not a probability distribution, but rather a deterministic set.

$>\quad$ In this paper, the uncertain parameter is the nodal net injection.
Proposes a two - stage adaptive RUC model for the SCUCP with nodal net injection uncertainty.

$>\quad$ The proposed model is more practical compared to other models since it requires only a deterministic uncertainty set rather than a hard - to - obtain probability distribution of uncertain parameters.

$>$ Develops a practical solution method using a combination of Benders' decomposition and the outer approximation technique.
> The uncertain wind power injections are assumed to be changeable within a polyhedron.

$>$ This polyhedron is specified by the deterministic [22] confidence bounds for each uncertain variable over the time horizon, which can be computed using statistical inference techniques based on historical data.
$>$ An RUC model is proposed for hybrid AC/DC transmission grids.

$>$ Full decomposition of network feasibility evaluation improves scalability.

$>$ Nonanticipativity is maintained using robust generator-wise reserve margins.

$>$ Improves hosting capacity and loadability for RES.
> The operation risk of load shedding and RE curtailment is reduced through the participation of [25] DR when the RE falls out of the adjustable uncertainty set.
> The uncertainty of RE in UC is dealt by the proposed adjustable uncertainty set.

$>\quad$ DR is co-optimized to reduce the operational risk of RE curtailment and load shedding.
$>$ Linear decision rules are used as an effective estimate to solve the multistage robust model, where decision variables are assumed to depend linearly on uncertain parameters.
$>$ Implements a rolling look-ahead UC scheme in a joint PDN and DHN to exploit the operational flexibility of rapid - response CHP units under substantially variable RES power output.

$>$ The scheme is formulated as a multistage distributionally robust commitment model that the non-anticipativity of decision variables for sequential revelations of uncertainties. $>\quad$ The uncertainty set in the proposed model is relevant and variable to the availability of system flexible resources.

[27] $>\quad$ The position and scale of the variable uncertainty set depend on the flexible reserve capacity and the system operation state.
> Proposes a flexible robust risk-constrained UC formulation where energy storage is allocated to cope with the uncertainty of wind power.

$>\quad$ The model creates an adjustable and flexible uncertainty set.

$>$ The model balances the operational risk and the operational costs. 
Table 13. Cont.

\begin{tabular}{lll} 
Ref. & \multicolumn{1}{c}{ Method Implementation } & \multicolumn{1}{c}{ Remarks } \\
\hline [29] $>\quad \begin{array}{l}\text { Uncertainty set is described as the convex hull of a } \\
\text { set of multivariate points representing RE profiles. } \\
\text { Historical daily profiles are used as scenarios, thus } \\
\text { embedding relevant information about the true } \\
\text { underlying uncertainty process in each vertex of } \\
\text { the uncertainty set. }\end{array}$ & $>\begin{array}{l}\text { Two - stage RUC models use an alternate scenario - based } \\
\text { framework to characterize uncertain renewable power generation } \\
\text { by a polyhedral uncertainty set. } \\
\text { The data - driven RUC protects against the convex hull of realistic } \\
\text { scenarios empirically capturing the time - varying and complex } \\
\text { intra - day spatial and temporal interdependencies between } \\
\text { renewable units. }\end{array}$
\end{tabular}

$>$ The formation of the partition - combine uncertainty set can be separated into three steps.

> First, the box set surrounding all the historical data is divided into subsets.

[31] > Second, the subsets with new developed boundaries are combined to reformulate the new uncertainty set.

$>$ Third, the inner subsets are found to reduce the scale of uncertainty variables.
RUC is conducted using the partition - combine - method to create the minimal uncertainty set with erratically distributed historical data. $>\quad$ The wind power system is assumed to receive no dispatch signals and generate unlimited power, whereas other energy systems are considered dispatchable.

> The uncertainty set contains three scenarios for wind power output. (predicted, error and extreme) $>\quad$ An RUC model for multiple energy sources based on the optimal uncertainty set is proposed.

$>\quad$ The RUC model is used to elucidate the effect of wind power fluctuations on power system scheduling. $>\quad$ The 1st and 2nd order moments of stochastic parameters can be assumed from historical data, and then employed to model the set of probability distributions.

[35] $>$ The resulting problem is a two - stage distributional RUC with 2nd order moment constraints, and it can be recast as MI - SDP with finite constraints. $>\quad$ The UC problem considering uncertainties of RES is examined using a distributionally robust optimization approach.

$>$ The solution algorithm of the problem solves a series of relaxed MI-SDPs and includes a subroutine of vertex generation and feasibility checking. $>\quad$ In the 1st stage, the energy, reserves and commitment of generators are pre - scheduled to minimize the operational cost, responding to the line failure scenario and worst load forecasting in a day of operations.

[36] $>\quad$ The 2nd stage constraint set includes the scheduling of generators, power flow, load shedding, generation curtailment after the realization of load forecasting errors and transmission line operating status.
$>$ A resilient UC problem is created as a two-stage DR\&RO problem.

- The formulated DR\&RO problem is resolved using the column and - constraint generation scheme and hybrid Benders' decomposition.
Zonal disaster - specific uncertainty sets are used to capture the dynamic behaviors of windstorms.

$>\quad$ The unavailability uncertainties of N-K contingencies, as well as the forecast uncertainties of wind power, PV power, and demand are considered.
$>$ A robust - resilient operational schedule for active distribution networks against windstorms is proposed.

$>$ Instead of committing microturbines and ESS in the 1st stage (here and - now) of the decision-making process, the proposed model considers related commitment decisions in the 2nd stage (wait and - see) of the decision - making process. This approach is more reliable with the short response time of these units.

$>$ A new solution that is based on LS and BCD techniques is suggested to solve the bi - level problem. 
Table 13. Cont.

\begin{tabular}{|c|c|c|c|c|}
\hline Ref. & & Method Implementation & & Remarks \\
\hline [38] & $>$ & $\begin{array}{l}\text { A data - driven, distance - based ambiguity set can } \\
\text { be constructed to capture the uncertainty of wind } \\
\text { power distribution. }\end{array}$ & $>$ & $\begin{array}{l}\text { Develops DDRC UC model. } \\
\text { The two - stage UC model aims on the commitment decision and } \\
\text { dispatch plan in the 1st stage and considers the worst - case } \\
\text { expected cost for a possible power imbalance or re - dispatch in the } \\
\text { 2nd stage. }\end{array}$ \\
\hline
\end{tabular}

$>$ The upper - level agent (the SO) determines the schedule of reserves and power so that the overall cost is minimized. This cost minimization problem is subjected to the worst - case contingency in each period and is modeled by the lower - level optimization.

$>$ The lower - level determines the combination of out - of - service generators so that the available post - contingency power output in each period is minimized. $>\quad$ A new approach for solving contingency - constrained single - bus $\mathrm{UCP}$ is presented

$>\quad$ The proposed model explicitly incorporates an $n-K$ security criterion by which the power balance is guaranteed under any contingency state that involves the simultaneous loss of up to $K$ generation units.

$>\quad$ The resulting model is a particular instance of bilevel programming and is solved by transforming it into an equivalent single - level MIP problem. $>\quad$ Different wind penetration levels are generated using PSO.

[82] $>$ In addition, 10\%, 15\%, 20\%, 25\%, 30\% and 35\% wind penetration are considered.
$>$ A PSO - based scenario reduction and generation algorithm is used to model uncertain parameters.

$>$ The stochastic UCP is solved using a new parameter - free self adaptive PSO algorithm.

$>\quad$ The 1st and 2nd order moments of the forecast errors for demand and wind power generation are needed, which are obtained from historical data instead of the predefined uncertainty sets.

$>$ The transmission power flow limits and generation output constraints are developed as chance constraints in which a flexible coefficient uses the robustness of the chance constraints to the forecast errors.

[85] $>$ The LMP uncertainty components for the transmission overloading and the generation violations are derived from the

Lagrangian function.

$>\quad$ These uncertainty components in the LMP represent the marginal contribution of the uncertainty in variable sources such as demand and wind power on the system cost.

$>$ A new electricity market - clearing mechanism that is based on LMPs is provided for pricing uncertain demand and generation.

- U - LMP is developed from a distributionally robust chance constrained optimal power flow model in which only the 1st order and 2nd order moments of the uncertain sources' probability distribution are required.
$>$ Implementation and development of two algorithms within a two - level framework.

[93] $>\quad$ The 1st stage decision variables should be made day-ahead while the 2nd stage decision variables should be made after wind power uncertainty is shown.
$>$ A two - stage robust UC model yields day-ahead generator schedules; wind uncertainty is captured by a polytropic uncertainty set.

$>$ Includes a DR strategy such that both generator schedules and price levels are obtained for the following day. $>\quad$ Feasibility and optimality cuts in Bender's

\section{[94] decomposition are considered}

$>\quad$ MCS is used to find the lower bound and upper bound of the wind power forecast. $>\quad$ Introduces an innovative min - max regret UC model to minimize the maximum regret of the day - ahead decision scheduling from the actual realization of the uncertain wind power generation.

- Benders' decomposition is developed to solve the problem. $>\quad$ Wind power forecast errors follow a normal distribution, and their first and second - order moments are allowed to change within predetermined regions.
A novel solution method of GRCC - RTD, considering wind power uncertainty, is proposed. 
Table 13. Cont.

\begin{tabular}{|c|c|c|c|c|}
\hline Ref. & & Method Implementation & & Remarks \\
\hline$[114]$ & $>$ & $\begin{array}{l}\text { The robustness of the PHEV transition model is } \\
\text { examined with respect to perturbations in } \\
\text { electricity prices. } \\
\text { The performance of the robust solution as a } \\
\text { function of the protection level for an emission } \\
\text { cost/credit. } \\
\text { Data uncertainty from both electricity grid and } \\
\text { transport sector are considered ( } 54 \text { parameters). }\end{array}$ & $>$ & $\begin{array}{l}\text { The method is based on comprehensive RO planning that considers } \\
\text { the constraints associated with both the transport sector and the } \\
\text { electricity grid. }\end{array}$ \\
\hline [115] & $>$ & $\begin{array}{l}\text { Offering curves are done based on price-taker } \\
\text { producer. The effectiveness of these curves aim to } \\
\text { achieve high profit. } \\
\text { Electricity prices are obtained using } \\
\text { ARIMA method. }\end{array}$ & $>$ & $\begin{array}{l}\text { Provides a technique for building hourly offering curves for a price } \\
\text { - taking producer that participates in a pool. } \\
\text { The technique relies on solving a sequence of robust } \\
\text { MILP problems. } \\
\text { Price confidence intervals are considered. }\end{array}$ \\
\hline
\end{tabular}

\subsection{Risk-Based Optimization}

Risk-based optimization is based on the definition of risk measures and associated optimization problem formulation that accounts for the risk induced in system-level outputs by uncertain parameters.

Table 14 presents studies in which risk-based optimization is used, and the risk considered. Risk-based optimization is performed by adding a penalty term in the objective function $[10,98]$, or by including the risk to constraints in the UCP $[28,84]$, or by doing both $[39,49,50,77]$. Additional constraints are defined in $[77,84]$ while others integrate the risk in the energy balance [98] and reserve constraint [28,49,50]. Wind power [10,28, $39,49,98]$, demand $[10,50,84]$, and failure of units $[28,49,77]$ are considered as uncertain parameters in the risk-based optimization.

Table 14. Studies In Which Risk-Based Optimization Is Used.

\begin{tabular}{|c|c|c|}
\hline Ref. & Risk Considered & Remarks \\
\hline [10] & $\begin{array}{l}>\quad \text { The risk considered are EENS, EWPC } \\
\text { and EOB. } \\
>\quad \text { EENS considers the load uncertainty } \\
\text { parameter. } \\
\text { EWPC considers the wind power } \\
\text { uncertainty. } \\
\text { EOB considers the power flow } \\
\text { uncertainty. } \\
\text { EENS, EWPC and EOB are considered to } \\
\text { the objective function as the penalty cost. }\end{array}$ & $\begin{array}{l}\text { Presents a novel RBDAUC model considering the risks of the } \\
\text { wind curtailment, branch overflow and loss of load. } \\
\text { The risks are expressed in using the probabilistic distributions } \\
\text { of the wind power generation forecast that are found in the } \\
\text { objective function and the constraints. } \\
\text { The RUC model is shown to be convex and is transformed into } \\
\text { a MILP problem using relaxation and piecewise linearization. }\end{array}$ \\
\hline [28] & $\begin{array}{l}\text { The PDF of the residual demand can be } \\
\text { obtained by the convolution of the PDFs } \\
\text { of the demand and the post curtailment } \\
\text { wind generation. } \\
\text { The residual demand is considered as the } \\
\text { operating risk and is integrated in the } \\
\text { reserve constraints. } \\
\mathrm{N}-1 \text { security stochastic criterion is also } \\
\text { considered in the reserve constraints. }\end{array}$ & $\begin{array}{l}>\quad \text { A new bi - objective PRCBUC model is developed to } \\
\text { simultaneously minimize the risks and operational costs. } \\
\text { The novel formulation of PRCBUC offers a new power } \\
\text { redispatch procedure to comply with the up - and - down } \\
\text { ramp rate constraints. } \\
>\quad \text { A new operational - cycles - based UC algorithm is developed. } \\
\text { The approach uses a new nondominated sorting backtracking } \\
\text { search optimization algorithm for extracting the } \\
\text { Pareto-optimal set. }\end{array}$ \\
\hline
\end{tabular}


Table 14. Cont.

\begin{tabular}{ll}
\hline Ref. & \multicolumn{1}{c}{ Risk Considered } \\
\hline$>\quad \begin{array}{l}\text { CVaR is adopted to specify the risk loss } \\
\text { when the wind power output falls } \\
\text { outside the predefined uncertainty set. }\end{array}>\begin{array}{l}\text { CVaR is defined as wind spillage and } \\
\text { load shedding cost and integrated in the } \\
\text { objective function. }\end{array}>\begin{array}{l}\text { A risk - based two - stage RUC model is developed to analyze } \\
\text { the admissibility of wind power generation. }\end{array}$ \\
$\begin{array}{l}\text { ESS is utilized to manage wind power uncertainty and reduce } \\
\text { the risk of loss. }\end{array}$
\end{tabular}

$>$ Cost of the down - spinning reserve is the penalty cost due to wind power (unavailability) and demand uncertainty (overestimating).

$>$ Cost of the up - spinning reserve is the penalty cost due to wind power uncertainty (overestimating) and [49] generation outage.

$>$ The risk constraint of load shedding is based on the up - spinning reserve.

$>$ The risk constraint of wind energy waste is based on the down - spinning reserve.

$>\quad \mathrm{N}-1$ condition is also considered in terms of the total up and down - spinning reserve.
$>$ A modified ED optimization model with wind power penetration is developed.

$>$ Underestimation and overestimation of the available wind power are offset by using up and down - spinning reserves.

$>$ Risk-based up and down - spinning reserve constraints are presented considering not only the uncertainty of available wind power generation but also the load forecast error and generator outage rates.

$>$ The predictor - corrector primal - dual interior - point (IP) method is applied to solve the ED model. $>\quad$ The reserve capacity constraint integrates the demand uncertain parameter in terms of RMSE.

[50] $>\quad$ The RMSE considers the line flow and power/required reserve.

$>$ The negative and positive reserve capacities are integrated into the objective function as the penalty cost.
$>$ A risk-based approach is presented to find the stochastic solution of NCUC when additional uncertainties are incorporated into the power system scheduling.

$>$ The NCUC problem is formulated as a single - stage - 2nd order cone program which is a convex algorithm.

$>$ The proposed method provides efficient solutions to large scale stochastic problems and aids to accommodate DER variabilities in economic and secure operations of power systems.
$>$ The UC risk considers the failure of generators, failure of lines, and risk of responsive demand.

$>\quad$ The UC risk is defined as a penalty cost in the objective function. $>\quad$ The Day-Ahead Demand Response Program is implemented as an incentive - based in providing the spinning reserve.

$>$ A certain number of demands are selected based on a sensitivity analysis and simulated as a virtual generation unit.

$>$ The reserve market is cleared for spinning reserve allocation using a probabilistic technique.

$>$ A comparison is made concerning economics and reliability between the absence and use of a Day - Ahead Demand Response Program.

\footnotetext{
$>$ A reliability constraint is accommodated [84] directly in terms of the power balance between supply and demand.
}

RLD is a new framework that integrates complex inputs and allows decision-makers to balance tradeoffs and quantify benefits that arise from increased flexibility and improved forecasting. 
Table 14. Cont.

\begin{tabular}{lll}
\hline Ref. & \multicolumn{1}{c}{ Risk Considered } & \multicolumn{1}{c}{ Remarks } \\
\hline & $>\quad \begin{array}{l}\text { Addresses a generic continuous - time risk - based model for } \\
\text { sub - hourly scheduling of energy generating units and bulk } \\
\text { ESUs in the day - ahead UCP. } \\
\text { The continuous - time risk - based UCP is modeled using } \\
\text { The curtailment of wind power is } \\
\text { included in the energy balance constraint. } \\
\text { The curtailment cost of wind turbine is } \\
\text { integrated in the objective function. }\end{array} \quad>\begin{array}{l}\text { The continuous - time risk - based model ensures that the } \\
\text { generating units and ESUs track the sub - hourly variations of } \\
\text { WPG, and the generation and demand are stable in each } \\
\text { sub-hourly interval. }\end{array}$ \\
\end{tabular}

\subsection{Hierarchical Scheduling Strategy}

A hierarchical scheduling strategy is the process of scheduling components or entities according to rank of importance. In a UCP, it can be carried out concerning committed generation units or reserve allocation $[23,24,88]$.

Table 15 presents studies in which the hierarchical scheduling strategy is used and how this method is implemented for uncertain parameters modeling. Power trading is implemented in [23] to manage the uncertainty of renewable energy and demand. In this study, the penalty cost of power trading between microgrids is implemented through the hierarchical approach considering the least cost. In [24], the author emphasize that the tie-line schedule is solved first before considering the generation schedule when a power interchange occurs during load uncertainty. Lastly, in [88], the study implements a hierarchical scheduling strategy considering generation reserve, ramping reserve, and transmission reserve. This method is implemented in the UCP using the energy balance constraint and penalty cost function.

Table 15. Studies In Which The Hierarchical Scheduling Strategy Is Used.

\begin{tabular}{|c|c|c|c|c|}
\hline Ref. & & Method Implementation & & Remarks \\
\hline [23] & $>$ & $\begin{array}{l}\text { ATC method is used to minimize the penalty cost of } \\
\text { power trading from different microgrids due to } \\
\text { uncertainty of demand and renewable energy (PV } \\
\text { and WP). }\end{array}$ & $\begin{array}{l}> \\
> \\
>\end{array}$ & $\begin{array}{l}\text { Solves the optimal operation problem for IMS in a market } \\
\text { environment with uncertainty. } \\
\text { Establishes a hierarchical distributed framework for cloud - } \\
\text { edge coordination. } \\
\text { Proposes a bi - level distributed optimization model with a fair } \\
\text { price mechanism. } \\
\text { ATC and augment Lagrange method are integrated. } \\
\text { The diagonal quadratic approximation is used to yield a } \\
\text { parallel solution. }\end{array}$ \\
\hline
\end{tabular}

- The hierarchical solution method considers net load uncertainties for several interconnected power systems.

$>$ An initial tie - line schedule and generation schedule for each area is derived. When a power interchange occurs, the tie - line schedule becomes the upper level problem followed by the generation schedule as the lower - level problem. $>\quad$ The problem is devised as a multi-area robust SCUC model, with a novel uncertainty set that is specified in terms of the variance of the system netload.

$>$ A modified outer approximation algorithm is developed to obtain a higher quality solution using bilinear programming. 
Table 15. Cont.

\begin{tabular}{cll}
\hline Ref. & \multicolumn{1}{c}{ Method Implementation } & \multicolumn{1}{c}{ Remarks } \\
\hline$>\quad \begin{array}{l}\text { The hierarchical scheduling strategy considers } \\
\text { both traditional and emergency operations. } \\
\text { The strategy separates the wind power output } \\
\text { into two intervals based on confidence levels } \\
\text { and applies various scheduling strategies in } \\
\text { different intervals of wind power output. }\end{array}>\begin{array}{l}\text { HUC model is presented to keep system security by } \\
\text { scheduling power system reserves with high penetration } \\
\text { of wind power generation. } \\
\text { The reserves in the HUC model include the generation } \\
\text { reserve, transmission reserve, and ramping reserve. }\end{array}$ \\
[88]
\end{tabular}

\subsection{Information Gap Decision Theory (IGDT)}

IGDT identifies the extent to which an uncertain parameter can function while ensuring that the minimum income is received by the decision - maker. Its two essential features are robustness and opportuneness. A detailed review of this approach can be found in the paper by Majidi et al. [133].

Table 16 presents the studies in which the IGDT method is used and how this method is implemented for uncertain parameters. The studies discussed in Table 16 consider a robust function wherein the uncertainty level is maximum when the function is maximized. The IGDT may be applied to the UCP by adding a penalty cost to the objective function; the IGDT's robust function is integrated into the energy balance constraint.

Table 16. Studies In Which IGDT Method Is Used.

\begin{tabular}{|c|c|c|}
\hline Ref. & Method Implementation & Remarks \\
\hline [70] & $\begin{array}{l}\text { IGDT is implemented modeling the load } \\
\text { demand and wind power generation } \\
\text { uncertainty by envelope bound method. } \\
\text { The uncertainty level is maximum when the } \\
\text { robust function is maximized. } \\
\text { The robust function is subjected to the energy } \\
\text { balance constraint wherein the minimum wind } \\
\text { power level and highest demand level } \\
\text { are considered. }\end{array}$ & $\begin{array}{l}\text { Presents a new framework, using IGDT, for the } \\
\text { multiobjective robust SCUC of generating units that are } \\
\text { connected to gridable vehicles and wind farms. } \\
\text { A bi - objective model is used in considering the } \\
\text { uncertainties cause by demand and wind power. } \\
\text { Normal boundary intersection technique is used to solve } \\
\text { the problem. }\end{array}$ \\
\hline [80] & $\begin{array}{l}\text { IGDT is implemented by maximizing the } \\
\text { uncertainty horizon of demand. } \\
\text { The model is subjected to the energy balance } \\
\text { constraint wherein the highest load level } \\
\text { is considered. }\end{array}$ & $\begin{array}{l}>\quad \text { Proposes a robust framework using IGDT for the SCUC of } \\
\text { generating units and lithium - ion BESS. } \\
\text { The cost of the degradation of the BESS is considered in } \\
\text { the objective function as an element that strongly } \\
\text { influences the BESS operation. } \\
>\quad \text { The framework is independent of PDFs or the } \\
\text { membership of sets and allows the SO to modify the } \\
\text { operating strategy (between over - conservative and } \\
\text { reckless) against the demand uncertainty. } \\
\text { The day - ahead scheduling problem is modeled as SCUC } \\
\text { using MILP. }\end{array}$ \\
\hline
\end{tabular}

\subsection{Discussion of Reviewed Methods}

A comprehensive review of the different studies and the method implementation were discussed in Sections 4.4-4.7. These include SP, probabilistic methods, CCP, RO, risk-based optimization, hierarchical scheduling strategy, and IGDT. SP is a method that optimizes the expected outcome on a risk-neutral perspective using a probability distribution. Commonly used PDFs are Gaussian, Rayleigh, Weibull, and Beta Distribution. In most cases, this method is transformed into a deterministic approach making it much simpler and easily implemented. Renewable energy and demand uncertainty are the most common areas 
of study that implement this method. The PDF can be formulated using historical data, forecasted data, or simulation results. Aside from using a given PDF, other ways of generating input are numerical and analytic methods which fall under the second discussed method which is the probabilistic method. This method together with SP has been applied by many studies involving outages, demand, and renewable uncertainty. Unfortunately, using these two methods may lead to an infeasible solution due to the constraint violation. In this case, the use of IGDT and CCP methods can be applied. These two methods can relax constraint violations by augmenting a penalty factor when these violations are relaxed.

$\mathrm{CCP}$ is an approach wherein a constraint violation is allowed. When these constraints are violated, a penalty cost is introduced on the UCP. Commonly used penalty costs are related to the load shedding and wind spillage of renewable energy spillage. Like the SP and probabilistic methods, the expected outcome can be compared over a known PDF or interval. Unfortunately, CCP does not consider the given interval or known PDF, resulting in a limitation of its flexibility and robustness. IGDT, on the other hand, like the CCP, allows constraint violations. The difference is that a robust function is implemented in IGDT. In this method, the framework is independent of the PDF or membership set and it allows the SO to vary the operating strategy easily.

The risk-based method, unlike the SP, optimizes the UCP using a risk-level approach. Most of the studies that applied this method involve the wind power and demand uncertainty. Unlike the SP, the reserve allocation in the UCP is fixed and cannot be adjusted; the risk-based optimization allows violations on constraints at a given risk level. Some risk-based methods consider the penalty cost while others just integrate it in the energy balance constraint or in the reserve constraint.

The other two methods discussed in Section 4 are the hierarchical scheduling strategy and RO. The hierarchical scheduling strategy is, unlike SP, CCP, and IGDT, a hierarchical process which is implemented to mitigate the effect of uncertainty. Reserve allocation is the common application of this method. RO solves the UCP by considering the worst-case scenario which may not be considered by the previous methods.

Lastly, since more uncertainty parameters in the UCP can be considered, it results in more data and variables to be considered. Different methods may be integrated together to increase computational efficiency.

\section{Evaluation of Constraints, Test System, and Simulation Tools of Different Studies}

Table 17 gives an outline of studies on the UCP that consider uncertainty. The constraints that are applied in the problem, along with the test system and the applied simulation tools, are shown in each scenario.

A variety of constraints are identified in the studies and the demand balance and constraints on thermal units are mentioned in most of them.

The studied systems range from simple systems to IEEE bus systems and sometimes real-life grids with periods of 4, 24, 168, and $8760 \mathrm{~h}$. Most of the studies involve the IEEE test system for $24 \mathrm{~h}$.

CPLEX and GUROBI have been the most used solvers to be implemented using C, $\mathrm{C}++$, Python, MATLAB, and GAMS. In most of the studies, MATLAB and GAMS have been used for simulation owing to their availability and ease of use. 
Table 17. Methods For UCP With Uncertainty Management.

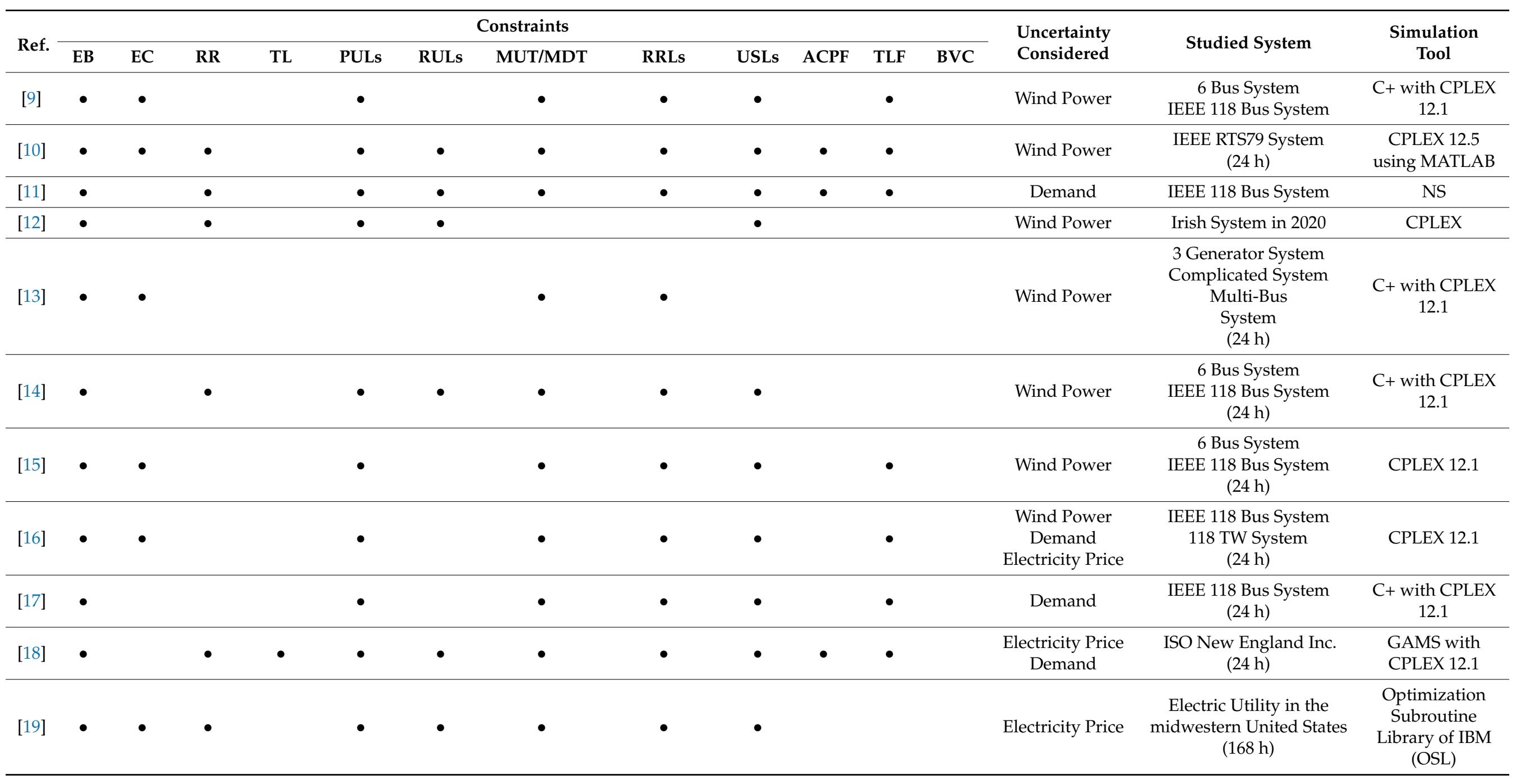


Table 17. Cont.

\begin{tabular}{|c|c|c|c|c|c|c|c|c|c|c|c|c|c|c|c|}
\hline \multirow{2}{*}{ Ref. } & \multicolumn{12}{|c|}{ Constraints } & \multirow{2}{*}{$\begin{array}{l}\text { Uncertainty } \\
\text { Considered }\end{array}$} & \multirow{2}{*}{ Studied System } & \multirow{2}{*}{$\begin{array}{c}\text { Simulation } \\
\text { Tool }\end{array}$} \\
\hline & EB & EC & $\mathbf{R R}$ & TL & PULs & RULs & MUT/MDT & RRLs & USLs & $\mathrm{ACPF}$ & TLF & BVC & & & \\
\hline [20] & & & & & $\bullet$ & & & & $\bullet$ & & & & $\begin{array}{l}\text { Outages of } \\
\text { Generation } \\
\text { Units }\end{array}$ & $\begin{array}{l}\text { Thermal generation mix } \\
\text { of Electricite de France } \\
(24 \mathrm{~h})\end{array}$ & NS \\
\hline [21] & & & & & $\bullet$ & & & & $\bullet$ & & & & $\begin{array}{c}\text { Outages of } \\
\text { Generation } \\
\text { Units } \\
\text { Demand } \\
\text { Electricity Price }\end{array}$ & $\begin{array}{c}\text { Michigan Electric Power } \\
\text { Coordination Center } \\
(168 \mathrm{~h})\end{array}$ & $\mathrm{C}$ \\
\hline [22] & $\bullet$ & • & $\bullet$ & • & • & • & $\bullet$ & • & $\bullet$ & • & • & $\bullet$ & $\begin{array}{l}\text { Renewable } \\
\text { Energy }\end{array}$ & $\begin{array}{c}2383 \text { Bus Test } \\
\text { Case-Polish } \\
\text { Transmission Grid } \\
(24 \mathrm{~h})\end{array}$ & $\begin{array}{l}\text { CPLEX and } \\
\text { MATLAB }\end{array}$ \\
\hline [23] & $\bullet$ & $\bullet$ & & & $\bullet$ & & & & & & & & $\begin{array}{l}\text { Renewable } \\
\text { Energy } \\
\text { Demand }\end{array}$ & $\begin{array}{c}\text { IM (Interconnected } \\
\text { Microgird) system } \\
\text { consisting of three MGs } \\
\text { (Microgrids) and an IMO } \\
\text { (Integrated Microgrid } \\
\text { System Operator) in a DN } \\
\text { (Distributed Network) } \\
(24 \mathrm{~h})\end{array}$ & $\begin{array}{l}\text { MATLAB } 2019 \\
\text { and Gurobi }\end{array}$ \\
\hline$[24]$ & $\bullet$ & $\bullet$ & & & $\bullet$ & & $\bullet$ & $\bullet$ & $\bullet$ & $\bullet$ & $\bullet$ & & Demand & $\begin{array}{c}2 \text { Area } 157 \text { Bus System } \\
\text { (IEEE } 39 \text { and 118) } \\
(24 \mathrm{~h})\end{array}$ & CPLEX 12.5 \\
\hline [25] & • & & & & $\bullet$ & & $\bullet$ & & • & & • & & $\begin{array}{l}\text { Renewable } \\
\text { Energy }\end{array}$ & $\begin{array}{c}\text { IEEE } 6 \text { Bus System } \\
\text { IEEE } 30 \text { Bus System } \\
\text { IEEE } 300 \text { Bus System } \\
(24 \mathrm{~h})\end{array}$ & $\begin{array}{l}\text { MATLAB with } \\
\text { YALMIP and } \\
\text { Gurobi }\end{array}$ \\
\hline [26] & $\bullet$ & & & & $\bullet$ & & $\bullet$ & $\bullet$ & • & & & & $\begin{array}{l}\text { Renewable } \\
\text { Energy }\end{array}$ & $\begin{array}{c}\text { Barry Island Multicarrier } \\
\text { Energy System } \\
(2 \mathrm{~h})\end{array}$ & CPLEX \\
\hline
\end{tabular}


Table 17. Cont.

\begin{tabular}{|c|c|c|c|c|c|c|c|c|c|c|c|c|c|c|c|}
\hline \multirow{2}{*}{ Ref. } & \multicolumn{12}{|c|}{ Constraints } & \multirow{2}{*}{$\begin{array}{l}\text { Uncertainty } \\
\text { Considered }\end{array}$} & \multirow{2}{*}{ Studied System } & \multirow{2}{*}{$\begin{array}{l}\text { Simulation } \\
\text { Tool }\end{array}$} \\
\hline & EB & EC & RR & TL & PULs & RULs & MUT/MDT & RRLs & USLs & ACPF & TLF & BVC & & & \\
\hline [27] & $\bullet$ & $\bullet$ & $\bullet$ & & $\bullet$ & $\bullet$ & $\bullet$ & $\bullet$ & $\bullet$ & $\bullet$ & $\bullet$ & & Wind Power & $\begin{array}{c}\text { IEEE } 39 \text { Bus System } \\
(24 \mathrm{~h})\end{array}$ & $\begin{array}{l}\text { YALMIP toolbox } \\
\text { in MATLAB and } \\
\text { CPLEX } 12.8\end{array}$ \\
\hline$[28]$ & $\bullet$ & & & & $\bullet$ & & & $\bullet$ & $\bullet$ & & & & $\begin{array}{l}\text { Wind Power } \\
\text { Demand } \\
\text { Outages of } \\
\text { Generation } \\
\text { Units }\end{array}$ & $\begin{array}{c}10 \text { Unit Test System } \\
\text { IEEE } 118 \text { Bus System } \\
(24 \mathrm{~h})\end{array}$ & $\begin{array}{l}\text { FORTRAN } \\
\text { Power Station }\end{array}$ \\
\hline [29] & $\bullet$ & & & & $\bullet$ & & $\bullet$ & $\bullet$ & $\bullet$ & & & & $\begin{array}{l}\text { Renewable } \\
\text { Energy } \\
\text { Demand }\end{array}$ & $\begin{array}{c}4 \text { Bus System } \\
\text { IEEE } 118 \text { Bus System } \\
(24 \mathrm{~h})\end{array}$ & $\begin{array}{c}\text { Gurobi 7.0.2 } \\
\text { under JuMP } \\
\text { (Julia 0.5) }\end{array}$ \\
\hline$[30]$ & $\bullet$ & $\bullet$ & $\bullet$ & & $\bullet$ & $\bullet$ & $\bullet$ & $\bullet$ & $\bullet$ & $\bullet$ & $\bullet$ & $\bullet$ & $\begin{array}{l}\text { Wind Power } \\
\text { Demand }\end{array}$ & $\begin{array}{c}\text { IEEE } 118 \text { Bus System } \\
(24 \mathrm{~h})\end{array}$ & $\begin{array}{l}\text { GAMS with } \\
\text { CPLEX }\end{array}$ \\
\hline [32] & $\bullet$ & $\bullet$ & $\bullet$ & & $\bullet$ & $\bullet$ & $\bullet$ & $\bullet$ & $\bullet$ & & & & $\begin{array}{l}\text { Renewable } \\
\text { Energy } \\
\text { Demand }\end{array}$ & $\begin{array}{l}\text { Power Grid of Southern } \\
\text { Island }\end{array}$ & CPLEX 12.1 \\
\hline$[33]$ & $\bullet$ & & $\bullet$ & & $\bullet$ & $\bullet$ & $\bullet$ & $\bullet$ & $\bullet$ & $\bullet$ & $\bullet$ & & Wind Power & $\begin{array}{c}3 \text { Bus System } \\
(4 \mathrm{~h})\end{array}$ & $\begin{array}{l}\text { CPLEX 10.2.0 } \\
\text { under GAMS }\end{array}$ \\
\hline [34] & $\bullet$ & $\bullet$ & $\bullet$ & & $\bullet$ & & & & & & $\bullet$ & & Wind Power & IEEE 39 Bus System & GAMS \\
\hline$[35]$ & $\bullet$ & & & & $\bullet$ & & $\bullet$ & $\bullet$ & $\bullet$ & & $\bullet$ & & $\begin{array}{l}\text { Renewable } \\
\text { Energy }\end{array}$ & $\begin{array}{l}\text { IEEE } 6 \text { Bus System } \\
\text { ( } 24 \mathrm{~h} \text { and } 30 \text { days) }\end{array}$ & $\begin{array}{c}\text { GUROBI 8.1.1 } \\
\text { and MOSEK8.1 }\end{array}$ \\
\hline$[36]$ & $\bullet$ & & $\bullet$ & & $\bullet$ & $\bullet$ & & $\bullet$ & $\bullet$ & & $\bullet$ & & $\begin{array}{c}\text { Disaster } \\
\text { (Hurricane) }\end{array}$ & $\begin{array}{c}\text { IEEE RTS } \\
\text { IEEE RTS-96 } \\
(24 \mathrm{~h})\end{array}$ & CPLEX \\
\hline [37] & $\bullet$ & $\bullet$ & & & $\bullet$ & & & & $\bullet$ & $\bullet$ & $\bullet$ & $\bullet$ & $\begin{array}{c}\text { Disaster } \\
\text { (Windstorms) } \\
\text { Wind Power PV } \\
\text { Power Demand }\end{array}$ & $\begin{array}{c}\text { IEEE } 33 \text { Bus System } \\
(24 \mathrm{~h})\end{array}$ & $\begin{array}{l}\text { GAMS using } \\
\text { CPLEX }\end{array}$ \\
\hline
\end{tabular}


Table 17. Cont.

\begin{tabular}{|c|c|c|c|c|c|c|c|c|c|c|c|c|c|c|c|}
\hline \multirow{2}{*}{ Ref. } & \multicolumn{12}{|c|}{ Constraints } & \multirow{2}{*}{$\begin{array}{l}\text { Uncertainty } \\
\text { Considered }\end{array}$} & \multirow{2}{*}{ Studied System } & \multirow{2}{*}{$\begin{array}{l}\text { Simulation } \\
\text { Tool }\end{array}$} \\
\hline & EB & EC & RR & TL & PULs & RULs & MUT/MDT & RRLs & USLs & ACPF & TLF & BVC & & & \\
\hline$[38]$ & $\bullet$ & & & & $\bullet$ & & $\bullet$ & $\bullet$ & $\bullet$ & & $\bullet$ & & Wind Power & $\begin{array}{c}\text { IEEE } 6 \text { Bus System } \\
\text { IEEE } 118 \text { Bus System } \\
(24 \mathrm{~h})\end{array}$ & $\begin{array}{l}\text { MATLAB with } \\
\text { YALMIP toolbox } \\
\text { using GUROBI }\end{array}$ \\
\hline [39] & $\bullet$ & & & & $\bullet$ & & $\bullet$ & & $\bullet$ & $\bullet$ & $\bullet$ & & Wind Power & $\begin{array}{c}6 \text { Bus System } \\
\text { IEEE } 118 \text { Bus System } \\
(24 \mathrm{~h})\end{array}$ & CPLEX 12.8 \\
\hline [42] & $\bullet$ & & & $\bullet$ & $\bullet$ & & & & & & & & Wind Power & NS & $\begin{array}{l}\text { MATLAB } \\
\text { Optimization } \\
\text { toolbox }\end{array}$ \\
\hline [43] & • & $\bullet$ & $\bullet$ & & $\bullet$ & $\bullet$ & $\bullet$ & $\bullet$ & $\bullet$ & & & & Wind Power & $\begin{array}{c}\text { NS } \\
(48 \mathrm{~h})\end{array}$ & NS \\
\hline [44] & • & $\bullet$ & $\bullet$ & & $\bullet$ & $\bullet$ & $\bullet$ & $\bullet$ & • & & $\bullet$ & & $\begin{array}{l}\text { Renewable } \\
\text { Energy }\end{array}$ & $\begin{array}{l}\text { IEEE RTS-24 System with } \\
20 \text { node gas network } \\
(24 \mathrm{~h})\end{array}$ & CPLEX 12.5 \\
\hline$[45]$ & $\bullet$ & & $\bullet$ & & $\bullet$ & & $\bullet$ & $\bullet$ & $\bullet$ & & $\bullet$ & & Wind Power & $\begin{array}{c}6 \text { Bus System } \\
\text { IEEE } 118 \text { Bus System } \\
(24 \mathrm{~h})\end{array}$ & CPLEX 12.4 \\
\hline$[47]$ & • & & & & $\bullet$ & & $\bullet$ & • & • & & & & Wind Power & $\begin{array}{l}\text { Isolated Power System } \\
(8760 \mathrm{~h})\end{array}$ & NS \\
\hline [48] & $\bullet$ & & & & $\bullet$ & & $\bullet$ & • & & & & & $\begin{array}{c}\text { Outages of } \\
\text { Generation } \\
\text { Units and } \\
\text { Transmission } \\
\text { Lines } \\
\text { Demand }\end{array}$ & $\begin{array}{l}6 \text { Bus System } \\
\text { IEEE } 118 \text { Bus System } \\
1168 \text { Bus System }\end{array}$ & NS \\
\hline
\end{tabular}


Table 17. Cont.

\begin{tabular}{|c|c|c|c|c|c|c|c|c|c|c|c|c|c|c|c|}
\hline \multirow{2}{*}{ Ref. } & \multicolumn{12}{|c|}{ Constraints } & \multirow{2}{*}{$\begin{array}{l}\text { Uncertainty } \\
\text { Considered }\end{array}$} & \multirow{2}{*}{ Studied System } & \multirow{2}{*}{$\begin{array}{l}\text { Simulation } \\
\text { Tool }\end{array}$} \\
\hline & EB & EC & $\mathbf{R R}$ & $\mathrm{TL}$ & PULs & RULs & MUT/MDT & RRLs & USLs & ACPF & TLF & BVC & & & \\
\hline [49] & $\bullet$ & & $\bullet$ & & $\bullet$ & $\bullet$ & & & & & & & $\begin{array}{l}\text { Wind Power } \\
\text { Demand } \\
\text { Outage of } \\
\text { Generation } \\
\text { Units }\end{array}$ & $\begin{array}{l}\text { Test System with } 10 \\
\text { conventional generator } \\
\text { and } 1 \text { windfarm }\end{array}$ & NS \\
\hline$[50]$ & $\bullet$ & & $\bullet$ & $\bullet$ & $\bullet$ & $\bullet$ & $\bullet$ & $\bullet$ & $\bullet$ & $\bullet$ & $\bullet$ & & Demand & $\begin{array}{c}\text { IEEE RTS-96 System } \\
\text { IEEE } 300 \text { Bus System } \\
(24 \mathrm{~h})\end{array}$ & Gurobi 7.5.1 \\
\hline [51] & $\bullet$ & $\bullet$ & $\bullet$ & & $\bullet$ & $\bullet$ & $\bullet$ & $\bullet$ & $\bullet$ & & $\bullet$ & & Wind Power & $\begin{array}{l}\text { IEEE RTS } 24 \text { Bus System } \\
(24 \mathrm{~h})\end{array}$ & NS \\
\hline [52] & $\bullet$ & $\bullet$ & & & $\bullet$ & & $\bullet$ & $\bullet$ & $\bullet$ & & & & $\begin{array}{c}\text { Renewable } \\
\text { Energy }\end{array}$ & NS & $\begin{array}{l}\text { Python with } \\
\text { GUROBI } 6.5 .1\end{array}$ \\
\hline [53] & $\bullet$ & $\bullet$ & $\bullet$ & & $\bullet$ & $\bullet$ & $\bullet$ & $\bullet$ & $\bullet$ & & & & $\begin{array}{c}\text { Demand } \\
\text { Wind Power } \\
\text { Outages of } \\
\text { Generation } \\
\text { Units } \\
\end{array}$ & $\begin{array}{l}\text { Simplified Illinois Power } \\
\text { System } \\
(744 \mathrm{~h})\end{array}$ & NS \\
\hline$[54]$ & $\bullet$ & $\bullet$ & $\bullet$ & & $\bullet$ & $\bullet$ & $\bullet$ & $\bullet$ & $\bullet$ & & & & $\begin{array}{l}\text { Outages of } \\
\text { Generation } \\
\text { Units } \\
\text { Demand }\end{array}$ & $\begin{array}{l}\text { IEEE Reliability Test } \\
\text { System } \\
(48 \mathrm{~h})\end{array}$ & NS \\
\hline [58] & $\bullet$ & $\bullet$ & $\bullet$ & $\bullet$ & $\bullet$ & $\bullet$ & $\bullet$ & $\bullet$ & $\bullet$ & $\bullet$ & $\bullet$ & $\bullet$ & Wind Power & $\begin{array}{c}\text { Portfolio } 5 \text { of All Island } \\
\text { Grid Study } \\
(24 \mathrm{~h})\end{array}$ & $\begin{array}{l}\text { GAMS with } \\
\text { CPLEX } 12\end{array}$ \\
\hline [59] & $\bullet$ & $\bullet$ & $\bullet$ & & $\bullet$ & $\bullet$ & & $\bullet$ & $\bullet$ & & & & $\begin{array}{l}\text { Outage of } \\
\text { Generation } \\
\text { Units }\end{array}$ & $\begin{array}{l}3 \text { Generator Unit System } \\
\text { Case Study built on a } \\
\text { Base Test System with } 10 \\
\text { generators (Real Size) }\end{array}$ & $\begin{array}{l}\text { Xpress-MP } 7.0 \\
\text { under MOSEL }\end{array}$ \\
\hline$[60]$ & $\bullet$ & $\bullet$ & & & $\bullet$ & & & & & & & & $\begin{array}{l}\text { Outages of } \\
\text { Generation } \\
\text { Units } \\
\text { Demand Wind } \\
\text { Power }\end{array}$ & $\begin{array}{c}\text { Generation System of a } \\
\text { medium-size Greek } \\
\text { Island } \\
(6 \mathrm{~h})\end{array}$ & NS \\
\hline
\end{tabular}


Table 17. Cont.

\begin{tabular}{|c|c|c|c|c|c|c|c|c|c|c|c|c|c|c|c|}
\hline \multirow{2}{*}{ Ref. } & \multicolumn{12}{|c|}{ Constraints } & \multirow{2}{*}{$\begin{array}{l}\text { Uncertainty } \\
\text { Considered }\end{array}$} & \multirow{2}{*}{ Studied System } & \multirow{2}{*}{$\begin{array}{l}\text { Simulation } \\
\text { Tool }\end{array}$} \\
\hline & EB & EC & $\mathbf{R R}$ & $\mathrm{TL}$ & PULs & RULs & MUT/MDT & RRLs & USLs & ACPF & TLF & BVC & & & \\
\hline [61] & $\bullet$ & & $\bullet$ & & $\bullet$ & $\bullet$ & & & & & $\bullet$ & & Electricity Price & 3 Bus System & NS \\
\hline [64] & $\bullet$ & $\bullet$ & $\bullet$ & & $\bullet$ & • & & $\bullet$ & • & & & & $\begin{array}{l}\text { Wind Power } \\
\text { Demand }\end{array}$ & $\begin{array}{c}\text { 10-Unit System } \\
(24 \mathrm{~h})\end{array}$ & $\begin{array}{l}\text { GAMS with } \\
\text { CPLEX } 11\end{array}$ \\
\hline$[65]$ & $\bullet$ & & & & $\bullet$ & & & & & & $\bullet$ & & Wind Power & $\begin{array}{l}\text { IEEE } 30 \text { Bus System } \\
(24 \mathrm{~h})\end{array}$ & $\begin{array}{c}\text { YALMIP toolbox } \\
\text { in MATLAB and } \\
\text { CPLEX }\end{array}$ \\
\hline$[66]$ & $\bullet$ & & $\bullet$ & & $\bullet$ & & $\bullet$ & $\bullet$ & $\bullet$ & & $\bullet$ & & $\begin{array}{l}\text { Wind Power } \\
\text { Demand } \\
\text { Outages of } \\
\text { Generation } \\
\text { Units }\end{array}$ & $\begin{array}{l}\text { IEEE Reliability Test } \\
\text { System } \\
(24 \mathrm{~h})\end{array}$ & $\begin{array}{l}\text { MATLAB with } \\
\text { CPLEX } 12.2\end{array}$ \\
\hline [67] & $\bullet$ & & $\bullet$ & & $\bullet$ & $\bullet$ & $\bullet$ & $\bullet$ & $\bullet$ & & & & $\begin{array}{c}\text { Outages of } \\
\text { Generation } \\
\text { Units } \\
\text { Wind Power PV } \\
\text { Power } \\
\text { Demand }\end{array}$ & Test System & MATLAB 2016a \\
\hline [69] & $\bullet$ & & $\bullet$ & & $\bullet$ & & $\bullet$ & $\bullet$ & $\bullet$ & & & & $\begin{array}{l}\text { Outages of } \\
\text { Generation } \\
\text { Units }\end{array}$ & $\begin{array}{l}\text { IEEE RTS } \\
(24 \mathrm{~h})\end{array}$ & $\begin{array}{l}\text { GAMS with } \\
\text { CPLEX } 12.7\end{array}$ \\
\hline$[70]$ & $\bullet$ & & & & $\bullet$ & & $\bullet$ & $\bullet$ & $\bullet$ & & • & & $\begin{array}{c}\text { PEV } \\
\text { Wind Power }\end{array}$ & $\begin{array}{c}6 \text { Bus System } \\
\text { IEEE RTS } 24 \text { Bus System } \\
\text { IEEE } 118 \text { Bus System } \\
(24 \mathrm{~h})\end{array}$ & $\begin{array}{l}\text { GAMS with } \\
\text { CPLEX }\end{array}$ \\
\hline$[71]$ & $\bullet$ & & $\bullet$ & & $\bullet$ & $\bullet$ & • & & & & & & Wind Power & $\begin{array}{l}\text { Typical MG Network } \\
\text { (24 h) }\end{array}$ & MATLAB \\
\hline$[72]$ & $\bullet$ & $\bullet$ & $\bullet$ & $\bullet$ & $\bullet$ & $\bullet$ & $\bullet$ & $\bullet$ & $\bullet$ & & & & $\begin{array}{c}\text { PEV } \\
\text { Demand } \\
\text { Wind Power }\end{array}$ & $\begin{array}{c}6 \text { Bus System } \\
118 \text { Bus System } \\
(24 \mathrm{~h})\end{array}$ & CPLEX 12.1 \\
\hline [73] & $\bullet$ & & & & $\bullet$ & & $\bullet$ & $\bullet$ & $\bullet$ & & & & Wind Power & $\begin{array}{l}\text { IEEE RTS } \\
(24 \mathrm{~h})\end{array}$ & $\begin{array}{l}\text { GAMS } 22.5 \text { with } \\
\text { CPLEX } 10.2\end{array}$ \\
\hline
\end{tabular}


Table 17. Cont.

\begin{tabular}{|c|c|c|c|c|c|c|c|c|c|c|c|c|c|c|c|}
\hline \multirow{2}{*}{ Ref. } & \multicolumn{12}{|c|}{ Constraints } & \multirow{2}{*}{$\begin{array}{l}\text { Uncertainty } \\
\text { Considered }\end{array}$} & \multirow{2}{*}{ Studied System } & \multirow{2}{*}{ Simulation Tool } \\
\hline & EB & EC & RR & TL & PULs & RULs & MUT/MDT & RRLs & USLs & ACPF & TLF & BVC & & & \\
\hline [75] & $\bullet$ & $\bullet$ & & & & & & & & & & & $\begin{array}{l}\text { Demand } \\
\text { PEV } \\
\text { PV }\end{array}$ & $\begin{array}{c}\text { Residential PV-Battery } \\
\text { System with EV } \\
(24 \mathrm{~h})\end{array}$ & MATLAB \\
\hline [76] & • & & & & $\bullet$ & & $\bullet$ & $\bullet$ & $\bullet$ & & $\bullet$ & & $\begin{array}{c}\text { Demand } \\
\text { Wind Power }\end{array}$ & $\begin{array}{l}\text { IEEE } 30 \text { Bus System } \\
\qquad(24 \mathrm{~h})\end{array}$ & CPLEX 12.1 \\
\hline [77] & • & & $\bullet$ & & & $\bullet$ & & & & & & & Demand & $\begin{array}{l}\text { IEEE } 57 \text { Bus System } \\
(24 \mathrm{~h})\end{array}$ & NS \\
\hline [79] & $\bullet$ & $\bullet$ & $\bullet$ & & $\bullet$ & $\bullet$ & $\bullet$ & $\bullet$ & $\bullet$ & & $\bullet$ & & $\begin{array}{l}\text { Wind Power } \\
\text { Demand }\end{array}$ & $\begin{array}{l}\text { IEEE } 118 \text { Bus System } \\
(24 \mathrm{~h})\end{array}$ & $\begin{array}{l}\text { GAMS with } \\
\text { CPLEX } 12.5\end{array}$ \\
\hline [80] & $\bullet$ & $\bullet$ & $\bullet$ & & $\bullet$ & $\bullet$ & $\bullet$ & $\bullet$ & $\bullet$ & $\bullet$ & $\bullet$ & & Demand & $\begin{array}{c}6 \text { Bus System } \\
\text { IEEE } 24 \text { Bus System } \\
\text { IEEE } 118 \text { Bus System } \\
(24 \mathrm{~h})\end{array}$ & $\begin{array}{l}\text { GAMS with } \\
\text { CPLEX }\end{array}$ \\
\hline [82] & $\bullet$ & & $\bullet$ & & $\bullet$ & $\bullet$ & $\bullet$ & $\bullet$ & $\bullet$ & & & & $\begin{array}{l}\text { Wind Power } \\
\text { Demand }\end{array}$ & $\begin{array}{c}12 \text { Generators and a } \\
\text { windfarm serving a load of } 8 \\
\text { GW } \\
(24 \mathrm{~h})\end{array}$ & NS \\
\hline [85] & $\bullet$ & $\bullet$ & & & $\bullet$ & & & & $\bullet$ & $\bullet$ & $\bullet$ & & Electricity Price & $\begin{array}{l}\text { PJM } 5 \text { Bus System } \\
\text { IEEE } 118 \text { Bus System } \\
(8760 \mathrm{~h})\end{array}$ & $\begin{array}{l}\text { GAMS with } \\
\text { MINOS }\end{array}$ \\
\hline [86] & $\bullet$ & $\bullet$ & $\bullet$ & $\bullet$ & $\bullet$ & $\bullet$ & $\bullet$ & $\bullet$ & $\bullet$ & $\bullet$ & $\bullet$ & $\bullet$ & PEV & $\begin{array}{l}\text { IEEE } 69 \text { Bus System } \\
(24 \mathrm{~h})\end{array}$ & NS \\
\hline [88] & $\bullet$ & $\bullet$ & $\bullet$ & & $\bullet$ & $\bullet$ & & $\bullet$ & $\bullet$ & & $\bullet$ & & Wind Power & $\begin{array}{c}8 \text { Bus System } \\
\text { Province level Power Grid in } \\
\text { China } \\
(24 \mathrm{~h})\end{array}$ & CPLEX 12.4 \\
\hline [89] & $\bullet$ & & $\bullet$ & & $\bullet$ & $\bullet$ & $\bullet$ & $\bullet$ & $\bullet$ & $\bullet$ & $\bullet$ & $\bullet$ & Wind Power & $\begin{array}{c}6 \text { Bus System } \\
118 \text { IEEE Bus System } \\
(24 \mathrm{~h})\end{array}$ & NS \\
\hline [91] & $\bullet$ & $\bullet$ & & & $\bullet$ & & $\bullet$ & $\bullet$ & & & & & Wind Power & NS & $\begin{array}{c}\text { AMPL } \\
\text { CBC Solver from } \\
\text { the COIN-OR } \\
\text { repository }\end{array}$ \\
\hline
\end{tabular}


Table 17. Cont.

\begin{tabular}{|c|c|c|c|c|c|c|c|c|c|c|c|c|c|c|c|}
\hline \multirow{2}{*}{ Ref. - } & \multicolumn{12}{|c|}{ Constraints } & \multirow{2}{*}{$\begin{array}{l}\text { Uncertainty } \\
\text { Considered }\end{array}$} & \multirow{2}{*}{ Studied System } & \multirow{2}{*}{$\begin{array}{c}\text { Simulation } \\
\text { Tool }\end{array}$} \\
\hline & EB & EC & $\mathbf{R R}$ & $\mathrm{TL}$ & PULs & RULs & MUT/MDT & RRLs & USLs & ACPF & TLF & BVC & & & \\
\hline [92] & $\bullet$ & & $\bullet$ & & $\bullet$ & $\bullet$ & $\bullet$ & $\bullet$ & $\bullet$ & $\bullet$ & $\bullet$ & & Wind Power & $\begin{array}{c}6 \text { Bus System } \\
\text { IEEE } 118 \text { Bus System } \\
(24 \mathrm{~h})\end{array}$ & CPLEX 12.1 \\
\hline [93] & $\bullet$ & & & & $\bullet$ & & $\bullet$ & $\bullet$ & $\bullet$ & & & & Wind Power & $\begin{array}{l}\text { IEEE } 118 \text { Bus System } \\
(24 \mathrm{~h})\end{array}$ & CPLEX 12.1 \\
\hline [94] & $\bullet$ & $\bullet$ & & & $\bullet$ & & $\bullet$ & $\bullet$ & $\bullet$ & $\bullet$ & $\bullet$ & & Wind Power & $\begin{array}{c}\text { IEEE-118 Bus System } \\
(24 \mathrm{~h})\end{array}$ & CPLEX 12.1 \\
\hline [96] & $\bullet$ & $\bullet$ & $\bullet$ & $\bullet$ & $\bullet$ & $\bullet$ & $\bullet$ & $\bullet$ & $\bullet$ & & & & Wind Power & $\begin{array}{c}\text { Denmark, Finland, } \\
\text { Germany, Norway, and } \\
\text { Sweden } \\
(168 \mathrm{~h})\end{array}$ & NS \\
\hline [97] & $\bullet$ & & & & $\bullet$ & & $\bullet$ & $\bullet$ & $\bullet$ & $\bullet$ & & & Wind Power & $\begin{array}{c}\text { IEEE } 118 \text { Bus System } \\
(24 \mathrm{~h})\end{array}$ & MATLAB \\
\hline [98] & $\bullet$ & & & & $\bullet$ & & $\bullet$ & $\bullet$ & $\bullet$ & & $\bullet$ & & Wind Power & $\begin{array}{c}\text { Modified IEEE RTS } \\
\text { Modified IEEE } 118 \text { Bus } \\
\text { System }\end{array}$ & CPLEX 12.6.2 \\
\hline [99] & $\bullet$ & $\bullet$ & $\bullet$ & & $\bullet$ & $\bullet$ & $\bullet$ & $\bullet$ & $\bullet$ & & & & Wind Power & $\begin{array}{c}\text { Single Bus Test System } \\
(12 \mathrm{~h})\end{array}$ & NS \\
\hline [100] & $\bullet$ & $\bullet$ & & & & & $\bullet$ & & & & & & Disaster & $\begin{array}{c}\text { Wind-Solar-Hydro } \\
\text { Hybrid System } \\
(24 \mathrm{~h})\end{array}$ & NS \\
\hline [101] & $\bullet$ & & $\bullet$ & & $\bullet$ & $\bullet$ & $\bullet$ & $\bullet$ & $\bullet$ & & $\bullet$ & & Wind Power & $\begin{array}{l}\text { 26-Generator System } \\
100 \text {-Generator System }\end{array}$ & NS \\
\hline [102] & $\bullet$ & & & & $\bullet$ & & & $\bullet$ & & & & & Wind Power & $\begin{array}{l}\text { Hubei Power Grid } \\
(24 \mathrm{~h})\end{array}$ & NS \\
\hline [103] & $\bullet$ & $\bullet$ & & & $\bullet$ & & $\bullet$ & $\bullet$ & $\bullet$ & $\bullet$ & $\bullet$ & & Wind Power & $\begin{array}{l}\text { IEEE RTS } \\
(24 \mathrm{~h})\end{array}$ & $\begin{array}{l}\text { GAMS with } \\
\text { CPLEX } 12.3\end{array}$ \\
\hline [105] & $\bullet$ & & & & $\bullet$ & & $\bullet$ & $\bullet$ & $\bullet$ & & & & $\begin{array}{l}\text { Electricity Price } \\
\text { Wind Power }\end{array}$ & NS & $\begin{array}{l}\text { GAMS with } \\
\text { CPLEX } 12\end{array}$ \\
\hline
\end{tabular}


Table 17. Cont.

\begin{tabular}{|c|c|c|c|c|c|c|c|c|c|c|c|c|c|c|c|}
\hline \multirow{2}{*}{ Ref. } & \multicolumn{12}{|c|}{ Constraints } & \multirow{2}{*}{$\begin{array}{l}\text { Uncertainty } \\
\text { Considered }\end{array}$} & \multirow{2}{*}{$\begin{array}{l}\text { Studied } \\
\text { System }\end{array}$} & \multirow{2}{*}{$\begin{array}{l}\text { Simulation } \\
\text { Tool }\end{array}$} \\
\hline & EB & EC & $\mathbf{R R}$ & TL & PULs & RULs & MUT/MDT & RRLs & USLs & ACPF & TLF & BVC & & & \\
\hline [106] & $\bullet$ & & $\bullet$ & & $\bullet$ & $\bullet$ & $\bullet$ & & $\bullet$ & & & & $\begin{array}{c}\text { PEV } \\
\text { Wind Power } \\
\text { Demand }\end{array}$ & $\begin{array}{l}10 \text { Unit } \\
\text { System } \\
(24 \mathrm{~h})\end{array}$ & MATLAB 7.8 \\
\hline [107] & • & & & & $\bullet$ & & & & & & & & $\begin{array}{l}\text { Renewable } \\
\text { Energy } \\
\text { Demand }\end{array}$ & $\begin{array}{l}\text { Fort Sill } \\
\text { Microgrid } \\
(24 \mathrm{~h})\end{array}$ & NS \\
\hline [111] & $\bullet$ & & & & $\bullet$ & & & & & & & & $\begin{array}{l}\text { Renewable } \\
\text { Energy } \\
\text { Demand }\end{array}$ & $\begin{array}{l}\text { East China } \\
\text { Power Grid } \\
\quad(24 \mathrm{~h})\end{array}$ & NS \\
\hline [113] & $\bullet$ & $\bullet$ & $\bullet$ & & $\bullet$ & $\bullet$ & $\bullet$ & $\bullet$ & $\bullet$ & & & & $\begin{array}{c}\text { Electricity Price } \\
\text { Renewable } \\
\text { Energy }\end{array}$ & $\begin{array}{l}\text { Standard } \\
\text { System } \\
(8760 \mathrm{~h})\end{array}$ & $\begin{array}{l}\text { MATLAB } \\
\text { GAMS }\end{array}$ \\
\hline [116] & $\bullet$ & $\bullet$ & & & $\bullet$ & & $\bullet$ & • & • & • & $\bullet$ & & $\begin{array}{l}\text { Random } \\
\text { Disaster }\end{array}$ & $\begin{array}{l}\text { IEEE } 118 \text { Bus } \\
\text { System }\end{array}$ & NS \\
\hline [119] & $\bullet$ & & $\bullet$ & & $\bullet$ & $\bullet$ & & $\bullet$ & • & & & & $\begin{array}{c}\text { PV Power } \\
\text { Wind Power }\end{array}$ & $\begin{array}{l}\text { Study System } \\
\quad(24 \mathrm{~h})\end{array}$ & MATLAB \\
\hline [135] & $\bullet$ & $\bullet$ & $\bullet$ & & $\bullet$ & $\bullet$ & $\bullet$ & & & & & & $\begin{array}{c}\text { PV Power } \\
\text { Wind Power }\end{array}$ & $\begin{array}{c}10 \text { unit } \\
\text { Benchmark } \\
\text { System }(24 \mathrm{~h})\end{array}$ & NS \\
\hline
\end{tabular}




\section{General Notes on Reviewed Methods}

Section 6 discusses some important issues regarding the reviewed methods. Table 18 summarizes all the reviewed studies in this paper in terms of method, solver, hardware specification, run - time, and simulation results. Based on Table 18, the following information can be summarized:

1. As the system size increases, the corresponding run - time also increases.

2. As more constraints are included in the UCP, the solution steps require a longer run time.

3. The modeling of uncertainty parameters affects the UCP result.

4. The CPLEX solver can be applied to any method.

5. The Gurobi solver is used on some methods where uncertainty can be adjusted; they include $\mathrm{CCP}$, risk-based optimization and $\mathrm{RO}$.

6. Advanced computing tools result in short run time regardless of methods applied.

7. SP has been used in the majority of the studies due to the short run - time. The drawback is it may result in a sub-optimal result or infeasible solution due to its limitation. SP combined with other methods will optimize the solution but increase the run time. This has been the commonly used strategy due to the advancement of computing tools.

8. RO has become of interest to a lot of researchers since it can handle more constraints compared to other methods. The only drawback to this method is its run - time, but this has already been solved due to more advanced computing tools.

Table 18. Summaries Regarding Methods, Hardware Specification, Run - time And Simulation Results.

\begin{tabular}{|c|c|c|c|c|}
\hline Method & Solver & Ref. & Hardware Specification & Run - Time, or Simulation Results \\
\hline $\mathrm{SP}$ & CPLEX & [12] & Intel Core Duo (1.83 MHz), 1 GB RAM & NS \\
\hline SP & CPLEX & {$[30]$} & Intel core i7-7700 (4.2 GHz), 32 GB RAM & $21.25 \mathrm{~s}$ \\
\hline SP & CPLEX & [44] & NS & $28.3 \mathrm{~min}$. in 153 iterations \\
\hline SP & CPLEX & {$[58]$} & Intel Xeon-W3520 (2.67 GHz), 12 GB RAM & $24 \mathrm{~h}$ \\
\hline $\mathrm{SP}$ & CPLEX & [72] & NS & NS \\
\hline SP & CPLEX & [73] & $\begin{array}{c}\text { 64-bit Dual Core (2.39 GHz) AMD } \\
\text { Opteron }\end{array}$ & NS \\
\hline SP & CPLEX & [83] & $\begin{array}{c}\text { Server using Linux with four } 3.0 \mathrm{GHz} \\
\text { processors, } 250 \mathrm{~GB} \text { RAM }\end{array}$ & NS \\
\hline SP & CPLEX & [103] & i5 with 4 cores $(3.2 \mathrm{GHz}), 4$ GB RAM & $1.155 \mathrm{~s}$ \\
\hline SP & OSL & [19] & NS & $553.1 \mathrm{~s}$ at 729 scenarios \\
\hline SP & СBC & [91] & $\begin{array}{l}350 \text { compute nodes (each with a } 2.4-\mathrm{GHz} \\
\text { Pentium Xeon and 1.5 GB RAM) }\end{array}$ & $32 \mathrm{CPUs}$ for $10 \mathrm{~h}$ \\
\hline ССР & CPLEX & [9] & $\begin{array}{l}\text { Computer workstation with } 4 \text { Intel Cores, } \\
\qquad 8 \text { GB RAM }\end{array}$ & $1364 \mathrm{~s}$ \\
\hline $\mathrm{CCP}$ & CPLEX & [13] & Workstation with 4 Intel Cores, 8 GB RAM & $1334.5 \mathrm{~s}$ \\
\hline ССР & CPLEX & {$[14]$} & Intel Quad Core (2.40 GHz), 8 GB RAM & $\begin{array}{c}6 \text { Bus System-0.02 s } \\
118 \text { Bus System-64.5 s }\end{array}$ \\
\hline
\end{tabular}


Table 18. Cont.

\begin{tabular}{|c|c|c|c|c|}
\hline Method & Solver & Ref. & Hardware Specification & Run - Time, or Simulation Results \\
\hline $\mathrm{CCP}$ & CPLEX & [40] & NS & $18.142 \mathrm{~s}$ \\
\hline CCP & CPLEX & {$[64]$} & $\begin{array}{c}\text { Intel Core Duo-E7500 (2.93 GHz), } 4 \text { GB } \\
\text { RAM }\end{array}$ & $\begin{array}{l}\text { Independent Constrained-11.8 s } \\
\text { Jointly Constrained-149 s }\end{array}$ \\
\hline $\mathrm{CCP}$ & CPLEX & [65] & NS & NS \\
\hline CCP & CPLEX & [79] & $3.10 \mathrm{GHz}, 8$ GB RAM & $\begin{array}{l}6 \text { Bus System-42.40 s } \\
118 \text { Bus System-1092 s }\end{array}$ \\
\hline $\mathrm{CCP}$ & Gurobi & {$[38]$} & Intel Core i7-6700 (3.40 GHz), 8 GB RAM & NS \\
\hline CCP & Gurobi & [52] & Intel Core i7-4790 (3.60 GHz), 16 GB RAM & $\begin{array}{l}397,696 \text { constraints }-889.24 \mathrm{~s} \\
389,952 \text { constraints }-160.69 \mathrm{~s}\end{array}$ \\
\hline $\mathrm{RO}$ & CPLEX & [15] & Intel Quad Core (2.40 GHz), 8 GB RAM & $\begin{array}{l}\text { No Uncertainty-1876 s } \\
50 \% \text { Uncertainty-3594 s }\end{array}$ \\
\hline $\mathrm{RO}$ & CPLEX & [16] & Intel Quad Core (2.40 GHz), 8 GB RAM & $1126 \mathrm{~s}$ \\
\hline $\mathrm{RO}$ & CPLEX & [18] & Intel Core 2 Duo (2.50 GHz), 3 GB RAM & NS \\
\hline $\mathrm{RO}$ & CPLEX & [22] & $\begin{array}{c}\text { Intel Core i7- } 7500 \mathrm{U} \text { Two Core }(2.70 \mathrm{GHz}) \\
16 \text { GB RAM }\end{array}$ & $500 \mathrm{~s} /$ iteration \\
\hline $\mathrm{RO}$ & CPLEX & [24] & Intel i5 (1.80 GHz), 8 GB RAM & $680 \mathrm{~s}$ for 3 iterations \\
\hline $\mathrm{RO}$ & CPLEX & [26] & Intel Core (3.2 GHz), 8 GB RAM & $\begin{array}{l}2 \text { Uncertainty Sets- }-0.36 \mathrm{~s} \\
20 \text { Uncertainty Sets-2.18 s }\end{array}$ \\
\hline $\mathrm{RO}$ & CPLEX & [27] & Intel Core i3, 8 GB RAM & $\begin{array}{l}\mathrm{UC}-3.50 \mathrm{~s}(\$ 485,195.9) \\
\text { FRRUC-38.23 s }(\$ 484,970.2)\end{array}$ \\
\hline $\mathrm{RO}$ & CPLEX & [32] & PC with a $2.2 \mathrm{GHz}, 4$ GB RAM & NS \\
\hline $\mathrm{RO}$ & CPLEX & [36] & NS & NS \\
\hline $\mathrm{RO}$ & CPLEX & [37] & Core i7 $(3.0 \mathrm{GHz}), 8$ GB RAM & NS \\
\hline $\mathrm{RO}$ & CPLEX & [93] & $\begin{array}{c}\text { Dell OPTIPLEX } 760(3.00 \mathrm{GHz}), 3 \text { GB } \\
\text { RAM }\end{array}$ & $\begin{array}{l}1 \text { Uncertainty Budget Constraint-85 s } \\
\text { (\$ 587,606) } \\
5 \text { Uncertainty Budget Constraint-622 } \\
\text { s }(\$ 580,419)\end{array}$ \\
\hline $\mathrm{RO}$ & CPLEX & {$[94]$} & Intel Quad Core (2.40 GHz), 8 GB RAM & $3468.16 \mathrm{~s}$ \\
\hline $\mathrm{RO}$ & CPLEX & [115] & $\begin{array}{c}\text { Server using Linux with four } 2.6 \mathrm{GHz} \\
\text { processors, } 32 \text { GB RAM }\end{array}$ & NS \\
\hline $\mathrm{RO}$ & Gurobi & [25] & $3.2 \mathrm{GHz}$ CPU, 32 GB RAM & NS \\
\hline $\mathrm{RO}$ & Gurobi & [29] & Xeon E5-2680 (2.5 GHz), 128 GB RAM & $\begin{array}{c}6 \text { Bus System-20 s } \\
118 \text { Bus System-774 s }\end{array}$ \\
\hline $\mathrm{RO}$ & Gurobi & [35] & Intel i5 CPU (1.80 GHz), 8 GB RAM & $\begin{array}{c}\mathrm{UC}-0.25 \mathrm{~s} \\
\text { RUC }-0.94 \mathrm{~s} \\
\text { DRUC }-271.57 \mathrm{~s}\end{array}$ \\
\hline $\mathrm{RO}$ & MOSEL & [59] & Intel Core i7 (3.2-GHz), 16 GB RAM & $\begin{array}{l}10 \text { Unit System-0.8 s } \\
100 \text { Unit System-33.6 s }\end{array}$ \\
\hline $\begin{array}{l}\text { Risk-based } \\
\text { Optimiza- } \\
\text { tion }\end{array}$ & CPLEX & [10] & $\begin{array}{l}\text { Windows-based PC with four threads (2.5 } \\
\text { GHz), } 4 \text { GB RAM }\end{array}$ & $\begin{array}{l}\text { DUC (5924 constraints)—5.52 s } \\
\text { RUC (15524 constraints)-10.4 s } \\
\text { SUC1 (70924 constraints)-286.39 s } \\
\text { SUC2 (77164 constraints) - } 518.75 \mathrm{~s}\end{array}$ \\
\hline $\begin{array}{l}\text { Risk-based } \\
\text { Optimiza- } \\
\text { tion }\end{array}$ & CPLEX & [39] & Intel Core i7-8700k, 16 GB RAM & $\begin{array}{c}6 \text { Bus System-0.172 s } \\
118 \text { Bus System-8.417 s }\end{array}$ \\
\hline $\begin{array}{l}\text { Risk-based } \\
\text { Optimiza- } \\
\text { tion }\end{array}$ & CPLEX & [98] & Intel Core-i7 (4.2 GHz), 32 GB RAM & $35 \mathrm{~min}$. \\
\hline
\end{tabular}


Table 18. Cont.

\begin{tabular}{|c|c|c|c|c|}
\hline Method & Solver & Ref. & Hardware Specification & Run - Time, or Simulation Results \\
\hline $\begin{array}{l}\text { Risk-based } \\
\text { Optimiza- } \\
\text { tion }\end{array}$ & Gurobi & {$[50]$} & Intel Xeon (3.50 GHz), 32 GB RAM & $325 \mathrm{~s}$ \\
\hline $\begin{array}{l}\text { Hierarchical } \\
\text { Scheduling } \\
\text { Strategy }\end{array}$ & CPLEX & {$[88]$} & Intel dual core ( $3.2 \mathrm{GHz}), 4$ GB RAM & $\begin{array}{c}\text { With Constraints } \\
\text { Simplification-40.33 s }(\$ 1,612,972) \\
\text { Without Constraints } \\
\text { Simplification-398.31 s }(\$ 1,612,436)\end{array}$ \\
\hline IGDT & CPLEX & {$[80]$} & Core i5, 4 GB RAM & NS \\
\hline $\mathrm{SP}$ and $\mathrm{RO}$ & CPLEX & [17] & 4 Intel Cores, 8 GB RAM & $\begin{array}{c}\mathrm{SP}-62 \mathrm{~s}(\$ 49,500) \\
\mathrm{SP} \text { and } \mathrm{RO}-50 \mathrm{~s}(\$ 49,500) \\
\mathrm{RO}-375 \mathrm{~s}(\$ 49,500)\end{array}$ \\
\hline $\begin{array}{l}\text { CCP and } \\
\text { RO }\end{array}$ & Gurobi & {$[38]$} & Core i7-6700 (3.40 GHz), 8 GB RAM & $\begin{array}{c}50 \text { Data Size-\$1,150,931.70 } \\
5000 \text { Data Size-\$1,144,773.40 }\end{array}$ \\
\hline $\begin{array}{l}\text { CCP and } \\
\text { RO }\end{array}$ & CPLEX & {$[45]$} & NS & NS \\
\hline $\begin{array}{l}\text { RO and } \\
\text { IGDT }\end{array}$ & CPLEX & {$[70]$} & Core i7 CPU, 16 GB RAM & NS \\
\hline $\begin{array}{l}\mathrm{CCP} \text { and } \\
\mathrm{RO}\end{array}$ & Minos & {$[85]$} & NS & $\begin{array}{c}\text { Gaussian Distribution-\$ } 54,165.50 \\
\text { Symmetrical Robustness— } \$ 57,524.10 \\
\text { Distributional Robustness-\$ } \\
59,636.10\end{array}$ \\
\hline
\end{tabular}

\section{Conclusions}

Uncertainty management in a UCP is crucial in the operations, control, and monitoring of power systems. It has attracted considerable attention since it influences the cost of the operation and maintenance of power grids. Considering the significance of this topic, this paper reviews a significant number of studies in this area.

The review identifies various types of uncertainty parameters and identifies how each is modeled. These types are technical, economic, and "epidemics, pandemics, and disasters". The latter category is found to be of great importance because this type cannot be modeled as simply as the first two types because it affects not only the techno-economic aspect of the energy sector but also the social aspect and thus, may lead to future studies.

This review examines various methods for uncertainty management and describes key concepts and innovations. The management of uncertainties related to renewable energy has seen an increase in studies conducted in recent years. These uncertainties arise from sustainable grid reconstruction and evolving environmental policies. In addition, the management of uncertainties related to electricity prices and demand continue to be of great importance today. These uncertainties arise from market liberalization and the increase in world population.

Computing tools such as GAMS and MATLAB are identified as the most used software tools, along with CPLEX or GUROBI solvers. For the studied system, IEEE test systems using 24-h intervals are easily implemented owing to data availability and their ease of use. A realistic test system (real power grid) should also be considered in conducting the uncertainty management of a UCP. Robust optimization has recently become a method of interest due to the availability of highly advanced computing tools. Lastly, this review shows how different studies propose policies or strategies in improving the control and operation for power systems. These strategies include the hierarchical scheduling of reserve, penalty cost for RE spillage and load shedding, and proper management of thermal units and ESS. 
Author Contributions: Conceptualization, Y.-Y.H.; methodology, G.F.D.A.; writing-original draft preparation, G.F.D.A.; supervision, Y.-Y.H.; funding acquisition, Y.-Y.H. All authors have read and agreed to the published version of the manuscript.

Funding: This research was funded by the Ministry of Science and Technology in Taiwan, grant number MOST 110-3116-F-008-001.

Institutional Review Board Statement: Not applicable.

Informed Consent Statement: Not applicable.

Data Availability Statement: Not applicable.

Acknowledgments: The authors would also like to thank the editors and reviewers for their valuable insight and suggestions on this paper.

Conflicts of Interest: The authors declare no conflict of interest.

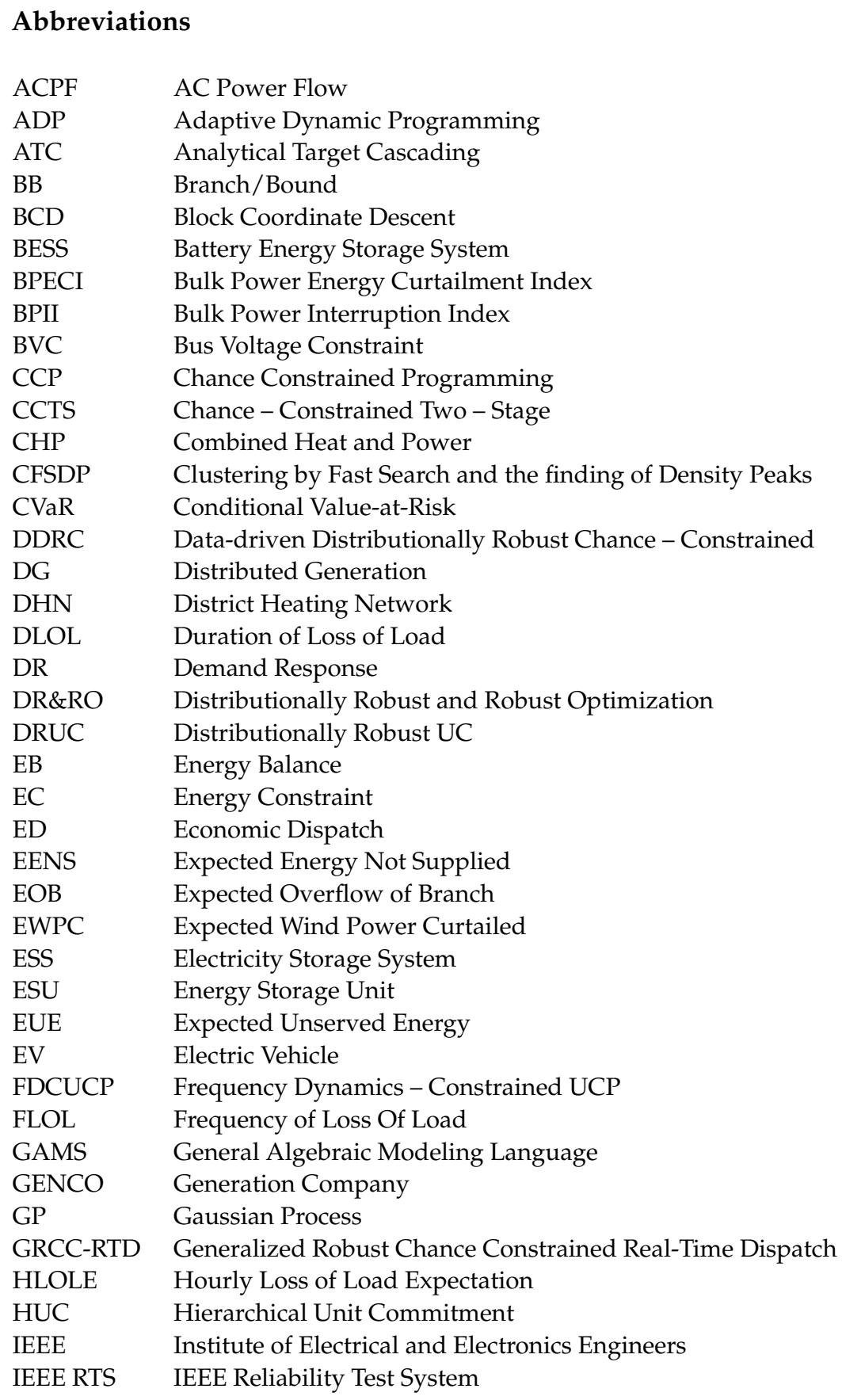




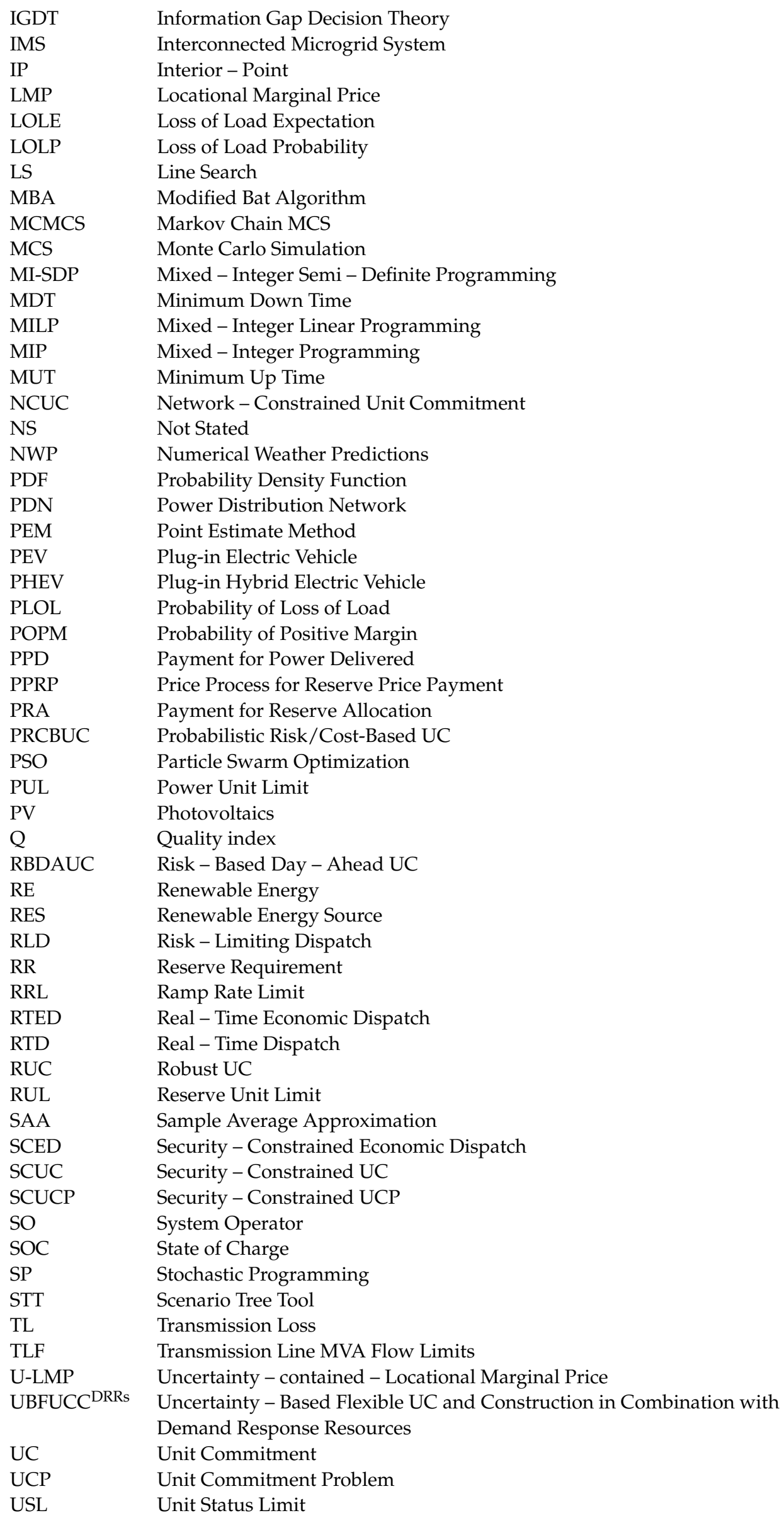




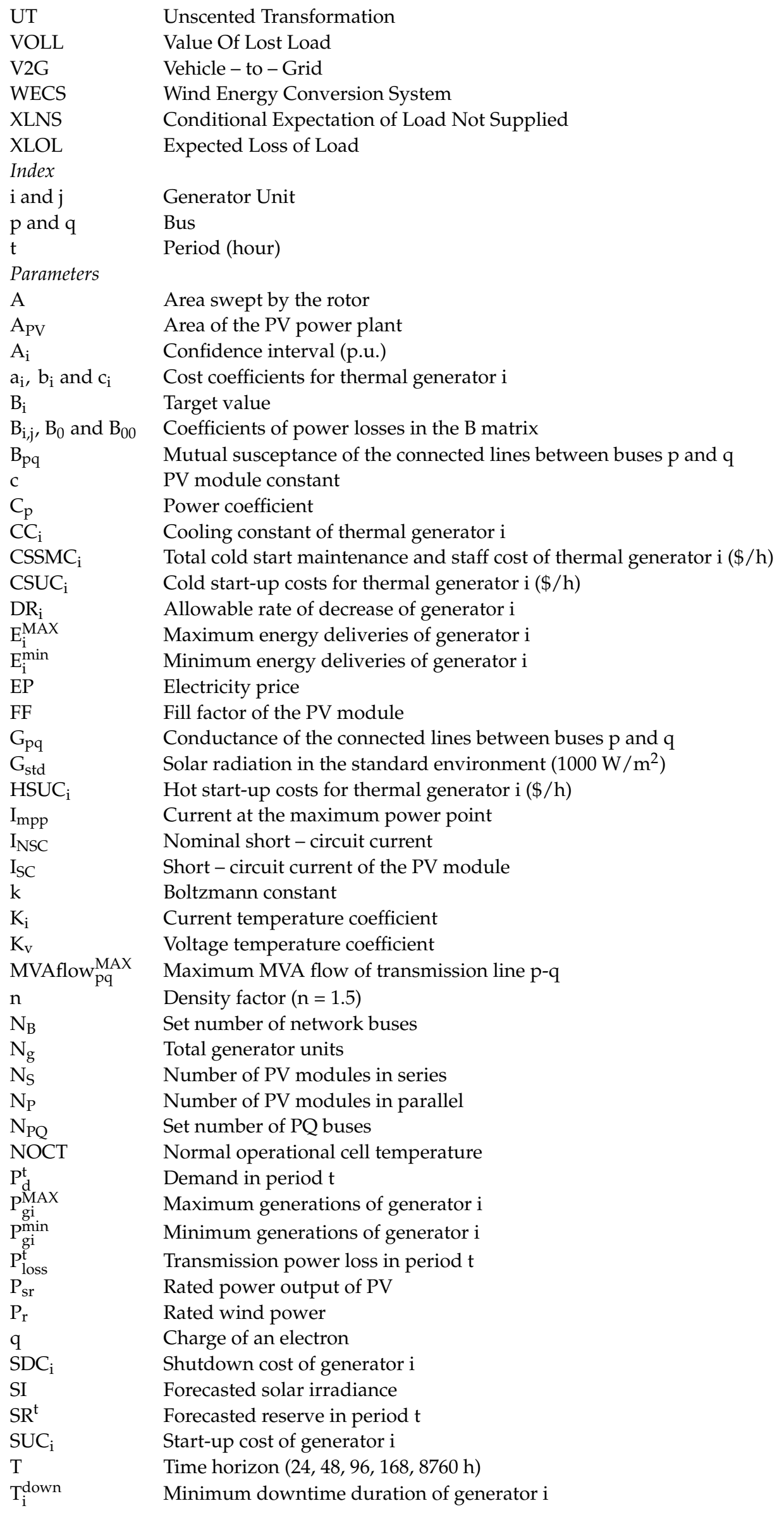




\begin{tabular}{|c|c|}
\hline $\mathrm{T}_{\mathrm{i}}^{\mathrm{up}}$ & Minimum uptime duration of generator i \\
\hline $\mathrm{UR}_{\mathrm{i}}$ & Allowable rate of increase of generator i \\
\hline $\mathrm{V}_{\mathrm{mpp}}$ & Voltage at the maximum power point \\
\hline $\mathrm{V}_{\mathrm{NOC}}$ & Nominal open - circuit voltage \\
\hline $\mathrm{V}_{\mathrm{OC}}$ & Open - circuit voltage of the PV module \\
\hline $\mathrm{V}_{\mathrm{q}}^{\mathrm{MAX}}$ & Allowable maximum voltage at bus $\mathrm{q}$ \\
\hline $\mathrm{V}_{\mathrm{q}}^{\mathrm{min}}$ & Allowable minimum voltage at bus $\mathrm{q}$ \\
\hline$x_{c}$ & Certain radiation point $\left(150 \mathrm{~W} / \mathrm{m}^{2}\right)$ \\
\hline$\alpha_{i}, \beta_{i}, \gamma_{i}, \xi_{i}$, and $\lambda_{i}$ & Emission coefficients for generator i \\
\hline$\theta_{\mathrm{pq}}$ & Voltage angle difference between buses $\mathrm{p}$ and $\mathrm{q}$ \\
\hline$\alpha$ & Scale parameter for the PDF of the Weibull function \\
\hline$\beta$ & Shape parameter for the PDF of the Weibull function \\
\hline$\beta_{\mathrm{T}}$ & PV temperature coefficient \\
\hline$\xi$ & Error of the function $\mathrm{f}_{\mathrm{i}}(\mathrm{x})$ \\
\hline$\zeta_{\mathrm{PV}}$ & Efficiency of the PV power plant \\
\hline$\mu_{\mathrm{D}}$ & Mean value of the load demand \\
\hline$\mu_{\mathrm{EP}}$ & Mean value of electricity price \\
\hline$\mu_{\mathrm{S}}$ & Mean deviation of solar irradiance \\
\hline$\mu_{\Delta \mathrm{P}_{\mathrm{L}}}$ & Mean value of load growth \\
\hline$\eta_{\mathrm{PV}}$ & Power reduction factor of photo-voltaic panels (\%) \\
\hline$\sigma_{\mathrm{D}}$ & Standard deviation of the load demand \\
\hline$\sigma_{\mathrm{EP}}$ & Standard deviation of electricity price \\
\hline$\sigma_{\mathrm{S}}$ & Standard deviation of solar irradiance \\
\hline$\sigma_{\Delta \mathrm{P}_{\mathrm{L}}}$ & Standard deviation of load growth \\
\hline$\omega$ & Wind speed $(\mathrm{m} / \mathrm{s})$ \\
\hline$\omega_{\mathrm{i}}$ & Cut - in wind speed $(\mathrm{m} / \mathrm{s})$ \\
\hline$\omega_{\mathrm{o}}$ & Cut - off wind speed $(\mathrm{m} / \mathrm{s})$ \\
\hline$\omega_{\mathrm{r}}$ & Rated wind speed (m/s) \\
\hline$\tau$ & Temperature \\
\hline$\tau_{\mathrm{a}}$ & Actual module temperature \\
\hline$\tau_{C}$ & Cell temperature \\
\hline$\tau_{\mathrm{N}}$ & Nominal module temperature \\
\hline$\rho$ & Air density \\
\hline Variables & \\
\hline$E_{\mathrm{i}}\left(\mathrm{P}_{\mathrm{gi}}^{\mathrm{t}}+\mathrm{R}_{\mathrm{gi}}^{\mathrm{t}}\right)$ & Emission function of generator $\mathrm{i}$ in period $\mathrm{t}$ \\
\hline$F_{i}\left(P_{g i}^{t}+R_{g i}^{t}\right)$ & Fuel cost of generator $\mathrm{i}$ in period $\mathrm{t}$ \\
\hline $\mathrm{f}_{\mathrm{EP}}$ & PDF of the electricity price \\
\hline $\mathrm{f}_{\mathrm{L}}$ & PDF of the load demand \\
\hline $\mathrm{f}_{\mathrm{S}}$ & PDF of the solar irradiance \\
\hline$f_{\omega}$ & PDF of the wind speed \\
\hline $\mathrm{f}\left(\mathrm{G}_{\mathrm{S}}\right)$ & PDF of $G_{s}$ \\
\hline $\mathrm{f}_{\Delta \mathrm{P}_{\mathrm{L}}}$ & PDF of the incremental load growth \\
\hline MVAflow $_{p q}^{t}$ & MVA flow of the power transmission line $\mathrm{p}-\mathrm{q}$ in period $\mathrm{t}$ \\
\hline$P_{g i}^{t}$ & Real power that is delivered by generator $\mathrm{i}$ in period $\mathrm{t}$ \\
\hline $\mathrm{P}_{\mathrm{gj}}^{\mathrm{t}}$ & Real power that is delivered by generator $\mathrm{j}$ in period $\mathrm{t}$ \\
\hline $\mathrm{P}_{\text {Bdp }}^{\mathrm{t}}$ & Absorbed active power at bus $p$ in period $t$ \\
\hline$P_{\text {Bgp }}^{t}$ & Generated active power at bus $\mathrm{p}$ in period $\mathrm{t}$ \\
\hline $\mathrm{P}_{\mathrm{W}}(\omega)$ & Output wind power $(\mathrm{kW}$ or MW) at wind speed $(\mathrm{m} / \mathrm{s})$ \\
\hline $\mathrm{P}_{\mathrm{PV}, \text { out }}$ & Output power of PV \\
\hline $\mathrm{P}_{\mathrm{a}}\left(\mathrm{G}_{\mathrm{s}}\right)$ & Average power output from a PV module for a given $\mathrm{G}_{\mathrm{S}}$ \\
\hline $\mathrm{Q}_{\mathrm{Bdp}}^{\mathrm{t}}$ & Absorbed reactive power at bus $\mathrm{p}$ in period $\mathrm{t}$ \\
\hline $\mathrm{Q}_{\mathrm{Bgp}}^{\mathrm{t}}$ & Generated reactive power at bus $\mathrm{p}$ in period $\mathrm{t}$ \\
\hline $\mathrm{R}_{\mathrm{gi}}^{\mathrm{t}}$ & Reserve of generator $\mathrm{i}$ in period $\mathrm{t}$ \\
\hline$S X_{i(O F F)}^{t}$ & Cumulative downtime of thermal generator $\mathrm{i}$ in period $\mathrm{t}$ \\
\hline $\mathrm{T}_{\mathrm{i}(\text { cold })}^{\mathrm{t}}$ & Time taken to cool thermal generator $\mathrm{i}$ in period $\mathrm{t}$ \\
\hline $\mathrm{T}_{\mathrm{i}(\text { down })}^{\mathrm{t}}$ & Time of downstate for thermal generator $\mathrm{i}$ in period $\mathrm{t}$ \\
\hline
\end{tabular}




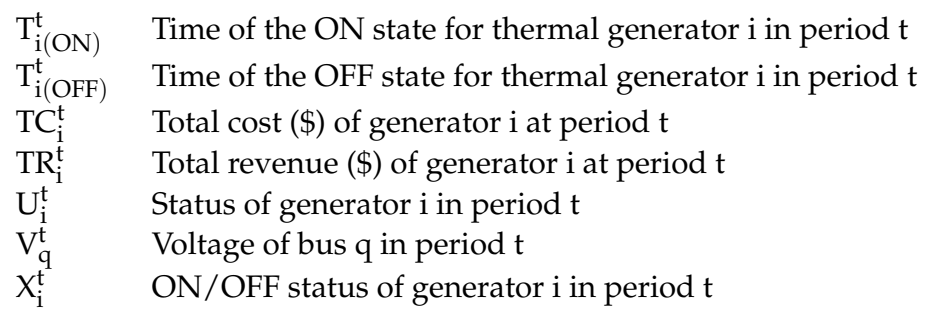

\section{References}

1. Ebeed, M.; Aleem, S.H.E.A. Overview of Uncertainties in Modern Power Systems: Uncertainty Models and Methods; Elsevier Inc.: Amsterdam, The Netherlands, 2021. [CrossRef]

2. OECD. The Impact of the Coronavirus (COVID-19) Crisis on Development Finance, Tackling Coronavirus Contribution to a Global Effort. 2020, Volume 100, pp. 468-470. Available online: http:/ / www.oecd.org/termsandconditions (accessed on 4 August 2021).

3. Emovon, I. A Fuzzy Multi-Criteria Decision-Making Approach for Power Generation Problem Analysis. J. Eng. Sci. 2020, 7, E26-E31. [CrossRef]

4. Kanagasabai, L. Heat Transfer and Simulated Coronary Circulation System Optimization Algorithms for Real Power Loss Reduction. J. Eng. Sci. 2021, 8, E1-E8. [CrossRef]

5. Abujarad, S.Y.; Mustafa, M.W.; Jamian, J.J. Recent approaches of unit commitment in the presence of intermittent renewable energy resources: A review. Renew. Sustain. Energy Rev. 2017, 70, 215-223. [CrossRef]

6. Dai, H.; Zhang, N.; Su, W. A Literature Review of Stochastic Programming and Unit Commitment. J. Power Energy Eng 2015, 3, 206-214. [CrossRef]

7. Jurković, K.; Pandžić, H.; Kuzle, I. Review on unit commitment under uncertainty approaches. In Proceedings of the 38th International Convention on Information and Communication Technology, Electronics and Microelectronics (MIPRO), Opatija, Croatia, 25-29 May 2015; pp. 1093-1097. [CrossRef]

8. Reddy, S.; Panwar, L.; Panigrahi, B.K.; Kumar, R.; Goel, L.; Al-Sumaiti, A.S. A profit-based self-scheduling framework for generation company energy and ancillary service participation in multi-constrained environment with renewable energy penetration. Energy Environ. 2020, 31, 549-569. [CrossRef]

9. Zhao, C.; Wang, Q.; Wang, J.; Guan, Y. Expected value and chance constrained stochastic unit commitment ensuring wind power utilization. IEEE Trans. Power Syst. 2014, 29, 2696-2705. [CrossRef]

10. Zhang, N.; Kang, C.; Xia, Q.; Ding, Y.; Huang, Y.; Sun, R.; Huang, J.; Bai, J. A Convex Model of Risk-Based Unit Commitment for Day-Ahead Market Clearing Considering Wind Power Uncertainty. IEEE Trans. Power Syst. 2015, 30, 1582-1592. [CrossRef]

11. Wang, Q.; Wang, J.; Guan, Y. Stochastic unit commitment with uncertain demand response. IEEE Trans. Power Syst. 2013, 28, 562-563. [CrossRef]

12. Tuohy, A.; Meibom, P.; Denny, E.; O'Malley, M. Unit Commitment for Systems with Significant Wind Penetration. IEEE Trans. Power Syst. 2009, 24, 592-601. [CrossRef]

13. Wang, Q.; Wang, J.; Guan, Y. Price-based unit commitment with wind power utilization constraints. IEEE Trans. Power Syst. 2013, 28, 2718-2726. [CrossRef]

14. Wang, Q.; Guan, Y.; Wang, J. A chance-constrained two-stage stochastic program for unit commitment with uncertain wind power output. IEEE Trans. Power Syst. 2012, 27, 206-215. [CrossRef]

15. Jiang, R.; Wang, J.; Guan, Y. Robust Unit Commitment with Wind Power and Pumped Storage Hydro. IEEE Trans. Power Syst. 2012, 27, 800-810. [CrossRef]

16. Zhao, C.; Wang, J.; Watson, J.P.; Guan, Y. Multi-stage robust unit commitment considering wind and demand response uncertainties. IEEE Trans. Power Syst. 2013, 28, 2708-2717. [CrossRef]

17. Zhao, C.; Guan, Y. Unified stochastic and robust unit commitment. IEEE Trans. Power Syst. 2013, 28, 3353-3361. [CrossRef]

18. Lorca, Á.; Sun, X.A.; Litvinov, E.; Zheng, T. Multistage adaptive robust optimization for the unit commitment problem. Oper. Res. 2016, 64, 32-51. [CrossRef]

19. Takriti, S.; Krasenbrink, B.; Wu, L.S.Y. Incorporating fuel constraints and electricity spot prices into the stochastic unit commitment problem. Oper. Res. 2000, 48, 268-280. [CrossRef]

20. Carpentier, P.; Cohen, G.; Culioli, J.C. Stochastic Optimization of Unit Commitment: A New Decomposition Framework. IEEE Trans. Power Syst. 1996, 11, 1067-1073. [CrossRef]

21. Takriti, S.; Birge, J.R.; Long, E. A stochastic model for the unit commitment problem. IEEE Trans. Power Syst. 1996, 11, 1497-1508. [CrossRef]

22. Isuru, M.; Hotz, M.; Gooi, H.B.; Utschick, W. Network-constrained thermal unit commitment fortexhybrid AC/DC transmission grids under wind power uncertainty. Appl. Energy 2020, 258, 114031. [CrossRef]

23. Kong, X.; Liu, D.; Wang, C.; Sun, F.; Li, S. Optimal operation strategy for interconnected microgrids in market environment considering uncertainty. Appl. Energy 2020, 275, 115336. [CrossRef]

24. Zheng, X.; Chen, H.; Xu, Y.; Liang, Z.; Chen, Y. A Hierarchical Method for Robust SCUC of Multi-Area Power Systems with Novel Uncertainty Sets. IEEE Trans. Power Syst. 2020, 35, 1364-1375. [CrossRef] 
25. Du, Y.; Li, Y.; Duan, C.; Gooi, H.B.; Jiang, L. Adjustable Uncertainty Set Constrained Unit Commitment with Operation Risk Reduced through Demand Response. IEEE Trans. Ind. Inform. 2021, 17, 1154-1165. [CrossRef]

26. Zhou, Y.; Shahidehpour, M.; Wei, Z.; Sun, G.; Chen, S. Multistage robust look-ahead unit commitment with probabilistic forecasting in multi-carrier energy systems. IEEE Trans. Sustain. Energy 2021, 12, 70-82. [CrossRef]

27. Zhang, G.; Li, F.; Xie, C. Flexible Robust Risk-Constrained Unit Commitment of Power System Incorporating Large Scale Wind Generation and Energy Storage. IEEE Access 2020, 8, 209232-209241. [CrossRef]

28. Bavafa, F.; Niknam, T.; Azizipanah-Abarghooee, R.; Terzija, V. A New Biobjective Probabilistic Risk-Based Wind-Thermal Unit Commitment Using Heuristic Techniques. IEEE Trans. Ind. Inform. 2017, 13, 115-124. [CrossRef]

29. Velloso, A.; Street, A.; Pozo, D.; Arroyo, J.M.; Cobos, N.G. Two-stage robust unit commitment for co-optimized electricity markets: An adaptive data-driven approach for scenario-based uncertainty sets. IEEE Trans. Sustain. Energy 2020, 11, 958-969. [CrossRef]

30. Naghdalian, S.; Amraee, T.; Kamali, S.; Capitanescu, F. Stochastic Network-Constrained Unit Commitment to Determine Flexible Ramp Reserve for Handling Wind Power and Demand Uncertainties. IEEE Trans. Ind. Inform. 2020, 16, 4580-4591. [CrossRef]

31. Zhang, M.; Fang, J.; Ai, X.; Zhou, B.; Yao, W.; Wu, Q.; Wen, J. Partition-Combine Uncertainty Set for Robust Unit Commitment. IEEE Trans. Power Syst. 2020, 35, 3266-3269. [CrossRef]

32. Wang, Y.; Dong, K.; Zeng, K.; Lan, X.; Zhou, W.; Yang, M.; Hao, W. Robust unit commitment model based on optimal uncertainty set. IEEE Access 2020, 8, 192787-192796. [CrossRef]

33. Morales, J.M.; Conejo, A.J.; Pérez-Ruiz, J. Economic valuation of reserves in power systems with high penetration of wind power. IEEE Trans. Power Syst. 2009, 24, 900-910. [CrossRef]

34. Liu, K.; Zhong, J. Generation dispatch considering wind energy and system reliability. In Proceedings of the IEEE PES General Meeting, Minneapolis, MN, USA, 25-29 July 2010; pp. 1-7. [CrossRef]

35. Zheng, X.; Chen, H.; Xu, Y.; Li, Z.; Lin, Z.; Liang, Z. A mixed-integer SDP solution to distributionally robust unit commitment with second order moment constraints. CSEE J. Power Energy Syst. 2020, 6, 374-383. [CrossRef]

36. Zhao, T.; Zhang, H.; Liu, X.; Yao, S.; Wang, P. Resilient Unit Commitment for Day-Ahead Market Considering Probabilistic Impacts of Hurricanes. IEEE Trans. Power Syst. 2021, 36, 1082-1094. [CrossRef]

37. Esfahani, M.; Amjady, N.; Bagheri, B.; Hatziargyriou, N.D. Robust Resiliency-Oriented Operation of Active Distribution Networks Considering Windstorms. IEEE Trans. Power Syst. 2020, 35, 3481-3493. [CrossRef]

38. Shi, Z.; Liang, H.; Dinavahi, V. Data-Driven Distributionally Robust Chance-Constrained Unit Commitment with Uncertain Wind Power. IEEE Access 2019, 7, 135087-135098. [CrossRef]

39. Zhang, Y.; Han, X.; Xu, B.; Wang, M.; Ye, P.; Pei, Y. Risk-Based Admissibility Analysis of Wind Power Integration into Power System with Energy Storage System. IEEE Access 2018, 6, 57400-57413. [CrossRef]

40. Wang, Y.; Zhao, S.; Zhou, Z.; Botterud, A.; Xu, Y.; Chen, R. Risk Adjustable Day-Ahead Unit Commitment with Wind Power Based on Chance Constrained Goal Programming. IEEE Trans. Sustain. Energy 2017, 8, 530-541. [CrossRef]

41. Poncelet, K.; Delarue, E.; D'haeseleer, W. Unit commitment constraints in long-term planning models: Relevance, pitfalls and the role of assumptions on flexibility. Appl. Energy 2020, 258, 113843. [CrossRef]

42. Hetzer, J.; Yu, D.C.; Bhattarai, K. An Economic Dispatch Model Incorporating Wind Power. IEEE Trans. Energy Convers. 2008, 23, 603-611. [CrossRef]

43. De Jonghe, C.; Hobbs, B.F.; Belmans, R. Value of price responsive load for wind integration in unit commitment. IEEE Trans. Power Syst. 2014, 29, 675-685. [CrossRef]

44. Xu, Y.; Ding, T.; Qu, M.; Du, P. Adaptive Dynamic Programming for Gas-Power Network Constrained Unit Commitment to Accommodate Renewable Energy with Combined-Cycle Units. IEEE Trans. Sustain. Energy 2020, 11, 2028-2039. [CrossRef]

45. Upadhyay, A.; Hu, B.; Li, J.; Wu, L. A chance-constrained wind range quantification approach to robust scuc by determining dynamic uncertainty intervals. CSEE J. Power Energy Syst. 2016, 2, 54-64. [CrossRef]

46. Wen, T.; Zhang, Z.; Lin, X.; Li, Z.; Chen, C.; Wang, Z. Research on Modeling and the Operation Strategy of a Hydrogen-Battery Hybrid Energy Storage System for Flexible Wind Farm Grid-Connection. IEEE Access. 2020, 8, 79347-79356. [CrossRef]

47. Pérez-Díaz, J.I.; Jiménez, J. Contribution of a pumped-storage hydropower plant to reduce the scheduling costs of an isolated power system with high wind power penetration. Energy 2016, 109, 92-104. [CrossRef]

48. Wu, L.; Shahidehpour, M.; Li, T. Stochastic Security-Constrained Unit Commitment. IEEE Trans. Power Syst. 2007, $22,800-811$. [CrossRef]

49. Zhou, W.; Sun, H.; Peng, Y. Risk reserve constrained economic dispatch model with wind power penetration. Energies 2010, 3, 1880-1894. [CrossRef]

50. Ghorani, R.; Pourahmadi, F.; Moeini-Aghtaie, M.; Fotuhi-Firuzabad, M.; Shahidehpour, M. Risk-Based Networked-Constrained Unit Commitment Considering Correlated Power System Uncertainties. IEEE Trans. Smart Grid. 2020, 11, 1781-1791. [CrossRef]

51. Li, N.; Uckun, C.; Constantinescu, E.M.; Birge, J.R.; Hedman, K.W.; Botterud, A. Flexible Operation of Batteries in Power System Scheduling with Renewable Energy. IEEE Trans. Sustain. Energy 2016, 7, 685-696. [CrossRef]

52. Marino, C.; Quddus, M.A.; Marufuzzaman, M.; Cowan, M.; Bednar, A.E. A chance-constrained two-stage stochastic programming model for reliable microgrid operations under power demand uncertainty. Sustain. Energy Grids Netw. 2018, 13, 66-77. [CrossRef]

53. Zhou, Z.; Botterud, A. Dynamic scheduling of operating reserves in co-optimized electricity markets with wind power. IEEE Trans. Power Syst. 2014, 29, 160-171. [CrossRef] 
54. Abdi, H. Profit-based unit commitment problem: A review of models, methods, challenges, and future directions. Renew. Sustain. Energy Rev. 2021, 138, 110504. [CrossRef]

55. Wu, C.X.; Chung, C.Y.; Wen, F.S.; Du, D.Y. Reliability/cost evaluation with pev and wind generation system. IEEE Trans. Sustain. Energy 2014, 5, 273-281. [CrossRef]

56. Ruiz, P.A.; Philbrick, C.R.; Zak, E.; Cheung, K.W.; Sauer, P.W. Uncertainty management in the unit commitment problem. IEEE Trans. Power Syst. 2009, 24, 642-651. [CrossRef]

57. Bouffard, F.; Galiana, F.D. Stochastic security for operations planning with significant wind power generation. In Proceedings of the IEEE Power and Energy Society General Meeting-Conversion and Delivery of Electrical Energy in the 21st Century, Pittsburgh, PA, USA, 20-24 July 2008; Volume 23, pp. 306-316. [CrossRef]

58. Lowery, C.; O’Malley, M. Impact of Wind Forecast Error Statistics Upon Unit Commitment. IEEE Trans. Sustain. Energy 2012, 3, 760-768. [CrossRef]

59. Jeong, J.; Park, S. A robust contingency-constrained unit commitment with an $\mathrm{N}-\alpha \mathrm{k}$ security criterion. Int. J. Electr. Power Energy Syst. 2020, 123, 1581-1590. [CrossRef]

60. Contaxis, G.C.; Kabouris, J. Short term scheduling in a wind/diesel autonomous energy system. IEEE Trans. Power Syst. 1991, 6, 1161-1167. [CrossRef]

61. Galiana, F.D.; Bouffard, F.; Arroyo, J.M.; Restrepo, J.F. Scheduling and pricing of coupled energy and primary, secondary, and tertiary reserves. Proc. IEEE 2005, 93, 1970-1982. [CrossRef]

62. Bouffard, F.; Galiana, F.D.; Conejo, A.J. Market-clearing with stochastic security-Part I: Formulation. IEEE Trans. Power Syst. 2005, 20, 1818-1826. [CrossRef]

63. Bouffard, F.; Galiana, F.D.; Conejo, A.J. Market-clearing with stochastic security-Part II: Case studies. IEEE Trans. Power Syst. 2006, 20, 1827-1835. [CrossRef]

64. Pozo, D.; Contreras, J. A chance-constrained unit commitment with an n-k security criterion and significant wind generation. IEEE Trans. Power Syst. 2013, 28, 2842-2851. [CrossRef]

65. Vrakopoulou, M.; Margellos, K.; Lygeros, J.; Andersson, G. A Probabilistic Framework for Reserve Scheduling and N-1 Security Assessment of Systems with High Wind Power Penetration. IEEE Trans. Power Syst. 2013, 28, 3885-3896. [CrossRef]

66. Liu, G.; Tomsovic, K. Quantifying Spinning Reserve in Systems With Significant Wind Power Penetration, IEEE Trans. Power Syst. 2012, 27, 2385-2393. [CrossRef]

67. Salkuti, S.R. Day-ahead thermal and renewable power generation scheduling considering uncertainty. Renew. Energy 2019, 131, 956-965. [CrossRef]

68. Osório, G.J.; Lujano-Rojas, J.M.; Matias, J.C.O.; Catalão, J.P.S. A probabilistic approach to solve the economic dispatch problem with intermittent renewable energy sources. Energy 2015, 82, 949-959. [CrossRef]

69. Wang, M.Q.; Yang, M.; Liu, Y.; Han, X.S.; Wu, Q. Optimizing probabilistic spinning reserve by an umbrella contingencies constrained unit commitment. Int. J. Electr. Power Energy Syst. 2019, 109, 187-197. [CrossRef]

70. Ahmadi, A.; Nezhad, A.E.; Siano, P.; Hredzak, B.; Saha, S. Information-Gap Decision Theory for Robust Security-Constrained Unit Commitment of Joint Renewable Energy and Gridable Vehicles. IEEE Trans. Ind. Inform. 2020, 16, 3064-3075. [CrossRef]

71. Khorramdel, H.; Aghaei, J.; Khorramdel, B.; Siano, P. Optimal Battery Sizing in Microgrids Using Probabilistic Unit Commitment. IEEE Trans. Ind. Inform. 2016, 12, 834-843. [CrossRef]

72. Khodayar, M.E.; Wu, L.; Shahidehpour, M. Hourly coordination of electric vehicle operation and volatile wind power generation in SCUC. IEEE Trans. Smart Grid. 2012, 3, 1271-1279. [CrossRef]

73. Restrepo, J.F.; Galiana, F.D. Assessing the yearly impact of wind power through a new hybrid deterministic/stochastic unit commitment. IEEE Trans. Power Syst. 2011, 26, 401-410. [CrossRef]

74. Ruiz-Rodriguez, F.J.; Hernández, J.C.; Jurado, F. Probabilistic load flow for photovoltaic distributed generation using the Cornish-Fisher expansion. Electr. Power Syst. Res. 2012, 89, 129-138. [CrossRef]

75. Langenmayr, U.; Wang, W.; Jochem, P. Unit commitment of photovoltaic-battery systems: An advanced approach considering uncertainties from load, electric vehicles, and photovoltaic. Appl. Energy 2020, 280, 115972. [CrossRef]

76. Wang, Y.; Xia, Q.; Kang, C. Unit Commitment with Volatile Node Injections by Using Interval Optimization. IEEE Trans. Power Syst. 2011, 26, 1705-1713. [CrossRef]

77. Shayesteh, E.; Yousefi, A.; Moghaddam, M.P. A probabilistic risk-based approach for spinning reserve provision using day-ahead demand response program. Energy 2010, 35, 1908-1915. [CrossRef]

78. Hou, Q.; Zhang, N.; Du, E.; Miao, M.; Peng, F.; Kang, C. Probabilistic duck curve in high PV penetration power system: Concept, modeling, and empirical analysis in China. Appl. Energy 2019, 242, 205-215. [CrossRef]

79. Zhang, Y.; Wang, J.; Zeng, B.; Hu, Z. Chance-Constrained Two-Stage Unit Commitment under Uncertain Load and Wind Power Output Using Bilinear Benders Decomposition. IEEE Trans. Power Syst. 2017, 32, 3637-3647. [CrossRef]

80. Ahmadi, A.; Nezhad, A.E.; Hredzak, B. Security-Constrained Unit Commitment in Presence of Lithium-Ion Battery Storage Units Using Information-Gap Decision Theory. IEEE Trans. Ind. Inform. 2019, 15, 148-157. [CrossRef]

81. Luo, L.; Abdulkareem, S.S.; Rezvani, A.; Miveh, M.R.; Samad, S.; Aljojo, N.; Pazhoohesh, M. Optimal scheduling of a renewable based microgrid considering photovoltaic system and battery energy storage under uncertainty. J. Energy Storage 2020, $28,101306$. [CrossRef] 
82. Swaroop, P.V.; Erlich, I.; Rohrig, K.; Dobschinski, J. A stochastic model for the optimal operation of a wind-thermal power system. IEEE Trans. Power Syst. 2009, 24, 940-950. [CrossRef]

83. Domínguez, R.; Carrión, M.; Oggioni, G. Planning and operating a renewable-dominated European power system under uncertainty. Appl. Energy 2020, 258, 113989. [CrossRef]

84. Entriken, R.; Varaiya, P.; Wu, F.; Bialek, J.; Dent, C.; Tuohy, A.; Rajagopal, R. Risk limiting dispatch. In Proceedings of the IEEE Power and Energy Society General Meeting, San Diego, CA, USA, 22-26 July 2012; pp. 1-5. [CrossRef]

85. Fang, X.; Hodge, B.M.; Du, E.; Kang, C.; Li, F. Introducing uncertainty components in locational marginal prices for pricing wind power and load uncertainties. IEEE Trans. Power Syst. 2019, 34, 2013-2024. [CrossRef]

86. Kavousi-Fard, A.; Niknam, T.; Fotuhi-Firuzabad, M. Stochastic Reconfiguration and Optimal Coordination of V2G Plug-in Electric Vehicles Considering Correlated Wind Power Generation. IEEE Trans. Sustain. Energy 2015, 6, 822-830. [CrossRef]

87. Wu, T.; Yang, Q.; Bao, Z.; Yan, W. Coordinated energy dispatching in microgrid with wind power generation and plug-in electric vehicles. IEEE Trans. Smart Grid. 2013, 4, 1453-1463. [CrossRef]

88. Zhou, B.; Geng, G.; Jiang, Q. Hierarchical unit commitment with uncertain wind power generation. IEEE Trans. Power Syst. 2016, 31, 94-104. [CrossRef]

89. Wang, J.; Shahidehpour, M.; Li, Z. Security-constrained unit commitment with volatile wind power generation. IEEE Trans. Power Syst. 2008, 23, 1319-1327. [CrossRef]

90. Khorramdel, B.; Raoofat, M. Optimal stochastic reactive power scheduling in a microgrid considering voltage droop scheme of DGs and uncertainty of wind farms. Energy 2012, 45, 994-1006. [CrossRef]

91. Constantinescu, E.M.; Zavala, V.M.; Rocklin, M.; Lee, S.; Anitescu, M. A computational framework for uncertainty quantification and stochastic optimization in unit commitment with wind power generation. IEEE Trans. Power Syst. 2011, 26, 431-441. [CrossRef]

92. Wu, L.; Shahidehpour, M.; Li, Z. Comparison of scenario-based and interval optimization approaches to stochastic SCUC. IEEE Trans. Power Syst. 2012, 27, 913-921. [CrossRef]

93. Zhao, L.; Zeng, B. Robust unit commitment problem with demand response and wind energy. In Proceedings of the IEEE Power and Energy Society General Meeting, San Diego, CA, USA, 22-26 July 2012; pp. 1-8. [CrossRef]

94. Jiang, R.; Wang, J.; Zhang, M.; Guan, Y. Two-stage minimax regret robust unit commitment. IEEE Trans. Power Syst. 2013, 28, 2271-2282. [CrossRef]

95. Methaprayoon, K.; Yingvivatanapong, C.; Lee, W.J.; Liao, J.R. An integration of ANN wind power estimation into unit commitment considering the forecasting uncertainty. IEEE Trans. Ind. Appl. 2007, 43, 1441-1448. [CrossRef]

96. Barth, R.; Brand, H.; Meibom, P.; Weber, C. A stochastic unit-commitment model for the evaluation of the impacts of integration of large amounts of intermittent wind power. In Proceedings of the International Conference on Probabilistic Methods Applied to Power Systems, Stockholm, Sweden, 11-15 June 2006. [CrossRef]

97. Zhu, X.; Yu, Z.; Liu, X. Security Constrained Unit Commitment with Extreme Wind Scenarios. J. Mod. Power Syst. Clean Energy 2020, 8, 464-472. [CrossRef]

98. Nikoobakht, A.; Aghaei, J.; Shafie-Khah, M.; Catalao, J.P.S. Minimizing Wind Power Curtailment Using a Continuous-Time Risk-Based Model of Generating Units and Bulk Energy Storage. IEEE Trans. Smart Grid. 2020, 11, 4833-4846. [CrossRef]

99. He, D.; Tan, Z.; Harley, R.G. Chance constrained unit commitment with wind generation and superconducting magnetic energy storages. In Proceedings of the IEEE Power and Energy Society General Meeting, San Diego, CA, USA, 22-26 July 2012; pp. 1-6. [CrossRef]

100. Huang, K.; Liu, P.; Ming, B.; Kim, J.S.; Gong, Y. Economic operation of a wind-solar-hydro complementary system considering risks of output shortage, power curtailment and spilled water. Appl. Energy 2021, 290, 116805. [CrossRef]

101. Venkatesh, B.; Yu, P.; Gooi, H.B.; Choling, D. Fuzzy MILP Unit Commitment Incorporating Wind Generators. IEEE Trans. Power Syst. 2008, 23, 1738-1746. [CrossRef]

102. Yang, Y.; Zhou, J.; Liu, G.; Mo, L.; Wang, Y.; Jia, B.; He, F. Multi-plan formulation of hydropower generation considering uncertainty of wind power. Appl. Energy 2020, 260, 114239. [CrossRef]

103. Kalantari, A.; Restrepo, J.F.; Galiana, F.D. Security-constrained unit commitment with uncertain wind generation: The loadability set approach. IEEE Trans. Power Syst. 2013, 28, 1787-1796. [CrossRef]

104. Williams, T.; Crawford, C. Probabilistic load flow modeling comparing maximum entropy and gram-charlier probability density function reconstructions. IEEE Trans. Power Syst. 2013, 28, 272-280. [CrossRef]

105. Khaloie, H.; Abdollahi, A.; Shafiekhah, M.; Anvari-Moghaddam, A.; Nojavan, S.; Siano, P.; Catalão, J.P.S. Coordinated windthermal-energy storage offering strategy in energy and spinning reserve markets using a multi-stage model. Appl. Energy 2020, 259, 114168. [CrossRef]

106. Zhang, N.; Hu, Z.; Han, X.; Zhang, J.; Zhou, Y. A fuzzy chance-constrained program for unit commitment problem considering demand response, electric vehicle and wind power. Int. J. Electr. Power Energy Syst. 2015, 65, 201-209. [CrossRef]

107. Soltani, N.Y.; Nasiri, A. Chance-Constrained Optimization of Energy Storage Capacity for Microgrids. IEEE Trans. Smart Grid. 2020, 11, 2760-2770. [CrossRef]

108. Zhou, A.; Yang, M.; Wang, Z.; Li, P. A linear solution method of generalized robust chance constrained real-time dispatch. IEEE Trans. Power Syst. 2018, 33, 7313-7316. [CrossRef] 
109. Wen, Y.; Li, W.; Huang, G.; Liu, X. Frequency Dynamics Constrained Unit Commitment with Battery Energy Storage. IEEE Trans. Power Syst. 2016, 31, 5115-5125. [CrossRef]

110. Kamjoo, A.; Maheri, A.; Putrus, G.A. Chance constrained programming using non-Gaussian joint distribution function in design of standalone hybrid renewable energy systems. Energy 2014, 66, 677-688. [CrossRef]

111. Zhu, F.; Zhong, P.; Xu, B.; Liu, W.; Wang, W.; Sun, Y.; Chen, J.; Li, J. Short-term stochastic optimization of a hydro-windphotovoltaic hybrid system under multiple uncertainties. Energy Convers. Manag. 2020, 214, 112902. [CrossRef]

112. Soleimanpour, N.; Mohammadi, M. Probabilistic load flow by using nonparametric density estimators. IEEE Trans. Power Syst. 2013, 28, 3747-3755. [CrossRef]

113. Roukerd, S.P.; Abdollahi, A.; Rashidinejad, M. Uncertainty-based unit commitment and construction in the presence of fast ramp units and energy storages as flexible resources considering enigmatic demand elasticity. J. Energy Storage 2020, $29,101290$. [CrossRef]

114. Hajimiragha, A.H.; Cañizares, C.A.; Fowler, M.W.; Moazeni, S.; Elkamel, A. A robust optimization approach for planning the transition to plug-in hybrid electric vehicles. IEEE Trans. Power Syst. 2011, 26, 2264-2274. [CrossRef]

115. Baringo, L.; Conejo, A.J. Offering strategy via robust optimization. IEEE Trans. Power Syst. 2011, 26, 1418-1425. [CrossRef]

116. Arab, A.; Khodaei, A.; Khator, S.K.; Han, Z. Electric Power Grid Restoration Considering Disaster Economics. IEEE Access 2016, 4, 639-649. [CrossRef]

117. Albrecht, P.F.; Garver, L.L.; Jordan, G.A.; Patton, A.D.; van Horne, P.R. Reliability Indexes for Power Systems. Final Report, March 1981; U.S. Department of Energy: Washington, DC, USA, 1981. [CrossRef]

118. Kayal, P.; Chanda, C.K. Placement of wind and solar based DGs in distribution system for power loss minimization and voltage stability improvement. Int. J. Electr. Power Energy Syst. 2013, 53, 795-809. [CrossRef]

119. Liang, R.H.; Liao, J.H. A fuzzy-optimization approach for generation scheduling with wind and solar energy systems. IEEE Trans. Power Syst. 2007, 22, 1665-1674. [CrossRef]

120. Shojaabadi, S.; Abapour, S.; Abapour, M.; Nahavandi, A. Simultaneous planning of plug-in hybrid electric vehicle charging stations and wind power generation in distribution networks considering uncertainties. Renew. Energy 2016, 99, $237-252$. [CrossRef]

121. Ali, E.S.; Elazim, S.M.A.; Abdelaziz, A.Y. Ant Lion Optimization Algorithm for optimal location and sizing of renewable distributed generations. Renew. Energy 2017, 101, 1311-1324. [CrossRef]

122. Gong, Q.; Lei, J.; Ye, J. Optimal siting and sizing of distributed generators in distribution systems considering cost of operation risk. Energies 2016, 9, 61. [CrossRef]

123. Reddy, S.S.; Bijwe, P.R.; Abhyankar, A.R. Real-Time Economic Dispatch Considering Renewable Power Generation Variability and Uncertainty over Scheduling Period. IEEE Syst. J. 2015, 9, 1440-1451. [CrossRef]

124. Suganthi, S.T.; Devaraj, D.; Ramar, K.; Thilagar, S.H. An Improved Differential Evolution algorithm for congestion management in the presence of wind turbine generators. Renew. Sustain. Energy Rev. 2018, 81, 635-642. [CrossRef]

125. Amrollahi, M.H.; Bathaee, S.M.T. Techno-economic optimization of hybrid photovoltaic/wind generation together with energy storage system in a stand-alone micro-grid subjected to demand response. Appl. Energy 2017, 202, 66-77. [CrossRef]

126. Pallabazzer, R. Evaluation of wind-generator potentiality. Sol. Energy 1995, 55, 49-59. [CrossRef]

127. Ali, A.; Raisz, D.; Mahmoud, K.; Lehtonen, M. Optimal Placement and Sizing of Uncertain PVs Considering Stochastic Nature of PEVs. IEEE Trans. Sustain. Energy 2020, 11, 1647-1656. [CrossRef]

128. Rawat, M.S.; Vadhera, S. Impact of Photovoltaic Penetration on Static Voltage Stability of Distribution Networks: A Probabilistic Approach. Asian J. Water Environ. Pollut. 2018, 15, 51-62. [CrossRef]

129. Salameh, Z.M.; Borowy, B.S.; Amin, A.R.A. Photovoltaic Module-Site Matching Based on the Capacity Factors. IEEE Trans. Energy Convers. 1995, 10, 326-332. [CrossRef]

130. Ruiz-Rodriguez, F.J.; Gomez-Gonzalez, M.; Jurado, F. Binary particle swarm optimization for optimization of photovoltaic generators in radial distribution systems using probabilistic load flow. Electr. Power Compon. Syst. 2011, 39, 1667-1684. [CrossRef]

131. Qian, K.; Zhou, C.; Allan, M.; Yuan, Y. Modeling of load demand due to EV battery charging in distribution systems. IEEE Trans. Power Syst. 2011, 26, 802-810. [CrossRef]

132. Zangeneh, A.; Jadid, S.; Rahimi-Kian, A. Uncertainty based distributed generation expansion planning in electricity markets. Electr. Eng. 2010, 91, 369-382. [CrossRef]

133. Majidi, B.; Mohammadi-Ivatloo, B.; Soroudi, A. Application of information gap decision theory in practical energy problems: A comprehensive review. Appl. Energy. 2019, 249, 157-165. [CrossRef]

134. Li, C.; Grossmann, I.E. A Review of Stochastic Programming Methods for Optimization of Process Systems Under Uncertainty. Front. Chem. Eng. 2021, 2, 1-20. [CrossRef]

135. Yang, Z.; Li, K.; Niu, Q.; Xue, Y. A comprehensive study of economic unit commitment of power systems integrating various renewable generations and plug-in electric vehicles. Energy Convers. Manag. 2017, 132, 460-481. [CrossRef] 